\title{
ACCIONES YDEUDA CORPORATIVA FINANCIERA (BONOS) EN LA ROMA CLÁSICA
}

\section{Guillermo Suárez Blázquez ${ }^{1}$}

\section{Resumen}

Nuestro estudio se dirige a analizar, desde una perspectiva histórico - jurídica y económica, a las sociedades de publicanos como entes jurídicos creadores de acciones, bonos y deuda corporativa financiera en la RomaClásica.

Palabras Claves: Acciones, Bonos corporativos, chirographa, syngrapha, societas publicanorum.

\section{INTRODUCCIÓN}

Tras una evolución histórica larga y compleja, los ordenamientos jurídicos modernos se basan en la existencia de dos posibles sujetos de derechos subjetivos: la persona física, el individuo humano, la persona natural, capaz de expresar una voluntad propia e individualizada, y las personas jurídicas, también denominadas sociales, colectivas o ficticias. En efecto, aunque no puede negarse que el Derecho es una creación humana al servicio del ser humano, en último término el único y verdadero sujeto, es también cierto que existen intereses colectivos y fines humanos de carácter social que exigen una actividad que excede de las posibilidades de un solo hombre. Esta necesidad de proteger la colaboración entre personas, en orden a la consecución de fines generales, se traduce en el mundo del Derecho en el reconocimiento de las personasjurídicas.

No cabe duda, por tanto, de la existencia de una profunda interrelación entre la creación romana de las corporaciones privadas de negocios públicos, dotadas de personalidad jurídica invisible, y el desarrollo económico y financiero del mundo moderno, a través de grandes corporaciones industriales, bancarias y de los negocios. Sociedades que son promovidas y financiadas mediante la suscripción de numerosas acciones y de bonos de deuda corporativa. Por este motivo, nuestro estudio se dirige a analizar la historia jurídica y ecónomica de las sociedades de publicanos como entes creadores de mercados financieros de capital y de deuda corporativa en la Roma Clásica.

\footnotetext{
${ }^{1}$ Catedrático Acreditado de Derecho Romano y Sistemas Jurídicos Contemporáneos (Universidad de Vigo). E-mail: gsuarez@uvigo.es
} 


\section{Consortium ercto non cito}

Notorio es el fragmento que nos reporta Gayo en sus Instituciones (3, 154a y 154b) sobre el origen y la naturaleza jurídica del contrato de sociedad:

"Sed ea quidem societas. Id est quae nudo consensu contrahitur, iuris gentium est, itaque inter omnes homines naturali ratione consistit. Est autem alius genus societatis propium civium Romanorum. Olim enim mortuo patre familias inter suos heredes quaedam erat legitima simul et naturalis societas, quae apellabatur ercto non cito, id est dominio non diviso: erctum enim dominium est, unde erus dominus dicitur: quoque, qui volebant eandem habere societatem, poterant id consequi apud praetorem certa legis actione. In hac autem societate fratrum suorum ceterorumque qui ad exemplum fratrum suorum societatem coierint, illud propium erat, quod vel unus ex sociis communem servum manumitiendo liberum faciebat et omnibus libertum adquirebat: item unus (rem communem mancipando eius faciebat, qui mancipio accipiebat...)".

En este fragmento Gayo nos transmite los orígenes y una línea orgánica evolutiva de la sociedad. Según el jurista el contrato de sociedad es una institución que surge del orden natural. Es fácil observar como muchas especies de animales se asocian para conseguir sus intereses naturales comunes: generalmente la persecución y captura de sus presas. El instinto natural de los seres vivos crea sociedades de ayuda y protección mutua. En este contexto, los hombres, en su condición de seres naturales, con independencia de su nacionalidad, se unen para lograr, mediante su esfuerzo, fines e intereses comunes. La sociedad no es una mera asamblea. La sociedad es, por naturaleza, un contrato consensual de aportación para la consecución de finalidad común 2 . En sintonía con esta tesis está la definición que nos reporta el Diccionario "A Latin Dictionary, Lewis and Short" (1º edición 1879, reimpresión New York 1989, p.1715) de la voz societas - is: union for a comon purpose. De acuerdo con los fragmentos anteriores, Gayo cree que la sociedad es congénita en todos los hombres: homines naturali ratione consistit. Institución que, además, fue históricamente adoptada por todos los derechos de los pueblos y naciones del Mundo Antiguo. La societas es una institución del Derecho natural, que fue conocida y, generalmente, regulada por el derecho propio de todas las naciones de la Antigüedad ${ }^{3}, y$ fue adoptada como contrato por el Ius Gentium romano, o Derecho internacional. Derecho al que numerosos juristas reputados del Commom law conocen como "The law of nations". En este sentido, Gayo sitúa al contrato de sociedad en el marco jurídico del "Law of nations". Sociedad que sería anterior incluso a la propia existencia de la civilización de Roma. Y es en este

\footnotetext{
${ }^{2}$ En este sentido, Daza MartínezJ.,y RodríguezEnnes L., Instituciones de Derecho PrivadoRomano, Valencia 2009, pp.379-380. ${ }^{3}$ San Isidoro, Etymologiae, V. QVID SIT IVS NATVRALE. [1] Ius autem naturale [est], aut civile, aut gentium. Ius naturale [est] commune omnium nationum, et quod ubique instinctu naturae, non constitutione aliqua habetur; ut viri et feminae coniunctio, liberorum successio et educatio, communis omnium possessio, et omnium una libertas, adquisitio eorum quae caelo, terra marique capiuntur:
} vol.09, no. 02, Rio de Janeiro, 2016.pp. 1075-1119 1076 
contexto como debemos entender la introducción del fragmento de Gayo sobre la naturaleza jurídica de la sociedad y su línea de desarrollo. Es decir, como institución del Derecho natural que es adoptada por el Ius Gentium de Roma, y éste, a su vez, como parte integrante de su Derecho Civil. Esta integración de la que da cuenta Cicerón ${ }^{4}$,fue acompañada por la nómina de otros contratos consensuales de buena fe, locatio conductio, emptio venditio y mandato ${ }^{5}$, que posibilitaron el florecimiento contractual internacional, inter gentes, de la sociedad, y el desarrollo del tráfico comercial terrestre y marítimo globalizado del Imperio. El contrato de mandato fue un instrumento decisivo para que la societas romana pudiese operar mediante mandatarios de otras nacionalidades ${ }^{6}$, posibilitando, de este modo, las importaciones y las exportaciones. También, en esta última línea de pensamiento, se sitúa V. Arangio Ruiz, quien cree que el contrato consensual de sociedad (la societas alicuis negotiationis tiene por fin la obtención de lucro) surge del negocio y del comerciointernacionales?

Por otra parte, el jurista Gayo afirma $\left(3,154^{a}\right.$ y $\left.3154 \mathrm{~b}\right)$ que en la Roma arcaica existía un género de sociedad hereditaria conocida como consortium ercto non cito (consorcio de dominio no divido). Con ello, quiso el jurista significar, aún admitiendo que la sociedad es una institución común a todos los pueblos, que Roma albergaba en su seno un género de sociedad civil y nacional propia, que surgía de forma automática entre los hermanos heredes sui a la muerte del común paterfamilias. Institución que, además, según Aulo Gelio constituyó una societas inseparabilis ${ }^{8}$. Tal vez, por el carácter hereditario primigenio del consortium debemos suponer que éste no fue el antecedente histórico jurídico romano que hizo surgir después a la societas como contrato iuris gentium. En este sentido, como ha puesto de relieve V. Arangio Ruiz, el consortium fue, muy probablemente, un condominio solidario sin cuotas que surgía, como hemos mencionado, de forma natural entre los heredes sui a la muerte del común paterfamilias 9 .

De acuerdo, con la opinión de V. Arangio Ruiz, el consortium se situaría en una posición próxima a los derechos reales, más que un contexto jurídico contractual y de obligaciones. Sin embargo, por su parte, S. Solazzi sostuvo que Gayo sí ubicó al consortium bajo un perfil contractual consensual. S. Solazzi cree que el consortium arcaico formado por extraños fue una societas que se podría establecer por el mero consentimiento de los partícipes. Estos últimos, además, estarían facultados para nombrar un administrador del consorcio y de establecer diferentes cuotas de participación en la sociedad fratris suorum. Sin embargo, V. Arangio Ruiz se opuso a esta tesis, pues sostiene que en materia del consortium ercto non cito "siamo di fronte ad un negocio formale". Piensa V. Arangio que su tesis se acomoda en Gayo quien reporta que para constituir un consortium no hereditario

\footnotetext{
${ }^{4}$ Cicerón, De Officis, 3.69 .

${ }^{5}$ Gayo, Inst. 3.135 .

${ }^{6}$ En este sentido, Volterra E., Instituciones de Derecho Privado Romano, ed. La Sapienza 1986, trad. J. Daza Martínez, Madrid 1988 , p.526.

${ }^{7}$ Arangio Ruiz V., “La Società in Diritto Romano”, primera edición 1965, reimpresión 2006. Nápoles, p 15.

${ }^{8}$ Aulo Gelio, Noctes Atticae, 1.9.

${ }^{9}$ Arangio Ruiz V., loc.cit. n.3, p. 15.
} 
voluntario era necesario el recurso a una certa legis actio. Acción de ley que es identificada por V. Arangio Ruiz en el proceso fingido de la in iure cessio. De modo que según V. Arangio "il consorte amministratore esiste solo nella fantasia di Solazzi ${ }^{10 "}$

Vemos que en los orígenes, la societas fratris que surge del consortium ercto non cito es concebida como un condominio (tal vez, un mancipium en común solidario) sin cuotas en el que participan todos los socios en la gestión y administración indistinta del capital y, del mismo modo, en su relación con terceros. El fin lícito del primigenio consortium no solo fue el mantenimiento del patrimonio familiar como un remedio efectivo frente a la división hereditaria sucesiva ruinosa del ager divisi et asignati entre los descendientes ${ }^{11}$ sino también la consecución de beneficios patrimoniales y pecuniarios para el condominio. En consecuencia, todos los actos de disposición patrimonial de un socio y las cargas, deudas y gravámenes afectaban en común a todos los demás consortes:
"In hac autem societate fratrum suorum ceterorumque qui ad exemplum fratrum suorum societatem coierint, illud proprium erat, quod vel unus ex sociis communem servum manumittendo liberum faciebat et omnibus libertum adquirebat: item unus (rem communem mancipando eius faciebat, qui mancipio accipiebat $\left.\left.(\ldots)^{12}\right)\right)^{\prime}$.

A pesar de las dudas que han sido suscitadas por la doctrina sobre la naturaleza jurídica del viejo consortium ercto non cito voluntario que se podía constituir por ciudadanos extraños, es decir, no ligados por vínculos de parentesco agnaticios (sociedad consensual para S. Solazzi ${ }^{13}$, bien negocio formal que constituye una sociedad que bordea, o incluso entronca con el mundo del condominio, es decir, de los derechos reales para $\mathrm{V}$. Arangio Ruiz), nosotros estimamos, de acuerdo con los fragmentos de las Instituciones de Gayo (III. 154a y 154b) que sí es seguro sostener que este consortium societario voluntario arcaico no gozó nunca de personalidad jurídica propia. Tampoco fue un ente jurídico independiente de los consortes que lo componían. Por último, este consortium societario tampoco fue titular de facultades subjetivas jurídicas como ente en sus relaciones comerciales con terceros. Sostener lo contario sería, sin duda, unanacronismo.

\section{Hacia el contrato clásico de sociedad iuris gentium (siglo II a.d. C. - siglo III d. C.)}

El consortium según cree V. Arangio Ruiz se proyectó en el tiempo y dejó su impronta en la nueva sociedad iuris gentium. Societas que estará ya operativa en los últimos siglos de la República. Así, según V. Arangio Ruiz si la societas omnium bonorum es heredera del viejo consortium ecto non cito hereditario, por su parte, la societas alicuis negotiationis surge del desarrollo del comercio internacional, en el que se verían implicados

\footnotetext{
${ }^{10}$ Ibidem, cit. pp. $15-16$.

${ }^{11}$ I bidem, cit. p. 19.

${ }^{12}$ Gayo, Inst. 3.154b.

${ }^{13}$ Solazzi S. "Peril XIV centenario della codificacione giustinianea" en Studi Pavia, 1934, p. 448 ss.
} 
hombres de diversas nacionalidades. Por otra parte, también según V. Arangio Ruiz la necesaria affectio societatis, elemento necesario para la constitución y el desarrollo de la sociedad, encontraría ya sus orígenes en la affectio fraternitatis de los hermanos heredes sui. Por último, la necesaria aportación de los socios de su patrimonio en común al capital social encontraría sus antecedentes en el condominio solidario que surgía de la unión de los socios en el consortium ercto non cito ${ }^{14}$.

Sin embargo, dejando aparte el problema de su naturaleza consensual, podríamos preguntarnos, ipor qué excluir de estos antecedentes al viejo consortium societatis conformado por extraños mediante el recurso a una legis actio certa? Precisamente, este consortium omnium bonorum (e incluso alicuis negotiationis) por ser realizado entre extraños se alejó del fin primigenio que trataba de mantener unido un patrimonio agrario, para extenderse ya a nuevos fines comerciales y pecuniarios.

A finales de la República, la conexión jurídica de la sociedad con la herencia fue reportada porCicerón:

"Simillima enim et maxime gemina societas hereditatis est: quem ad modum socius in societate habet partem, sic heres in hereditate habet partem. Ut heres sibi soli non coheredibus petit, sic socius sibi soli non sociis petit; et quem ad modum uterque pro sua parte petit, sic pro sua parte dissolvit, heres ex ea parte qua hereditatem adiit, socius ex ea qua societatem coiit ${ }^{15}$.

Cicerón cree que la sociedad es una institución similar, incluso gemela de la herencia. Ambas anclan sus raíces en el ius naturale. Cicerón, en De finibus, 4, 2, 4, afirma: societas generis humani, quam conciliavit ipsa natura. De la misma forma en Laelius de amicitia, 5,2: fides et societas generis humani. También Gayo ${ }^{16}(\mathrm{mitad}$ siglo II d.C. aprox.) opina que el Derecho natural es el generador de la societas, y, precisamente el consortium hereditario ercto non cito fue una societas naturalis. Por su parte, nuestro S. Isidoro de Sevilla ${ }^{17}$ (560 d.C.- 636 d.C.) reporta en sus Etymologiarum sive Originum, que la sucessio liberorum forma parte del ius naturale. La línea de pensamiento filosófica y jurídica, clásica y postclásica, romana sitúa a la sociedad y a la hereditas en el mismo origen común: el Ius Naturale.

Además, según el estadista de Arpino, de la misma forma que el socio tiene una parte en el capital social, el heredero tiene una cuota la herencia. Si un heredero pide judicialmente (hereditatis petitio) lo hace en su nombre, no en el nombre de los demás coherederos. Del mismo modo, socius sibi soli non sociis petit. Si un socio exige judicialmente su cuota proporcional, tan solo pro sua parte dissolvit. Por último, el heredero exige la cuota que aceptó en la herencia. De la misma forma, el socio demanda la cuota por la que contrajo sociedad.

En esta dirección, la fraternitas de los herederos del arcaico consortium ercto non cito es un elemento que será heredado por el contrato de sociedad iuris gentium. Elemento necesario para el desarrollo de la vida de la

\footnotetext{
${ }^{14}$ Arangio Ruiz V.cit.pp. $20-21$.

${ }^{15}$ Cicerón, Pro Q. Roscio, I.55.

${ }^{16}$ Gayo, Inst. 3.154a.

${ }^{17}$ S. Isidoro, Etymolgiae, V.4.
} 
sociedad tanto en la época republicana como en la etapa clásica (societas ius quodammodo fraternitatis in se habeat, Ulpiano libro XXXI ad edictum ${ }^{18}$ ). Y, aunque la sociedad toma elementos de la vieja societas naturalis hereditaria arcaica, la República abre un nuevo periodo histórico de apertura y dominio imperial y de expansión económica de libre cambio comercial, mercantil y monetario que creará nuevas estructuras e instituciones. Así, desde el punto de vista de la sociedad, Roma adoptará el consenso, la affectio ${ }^{19}$ y la buena fe continuadas ${ }^{20}$, como elementos jurídicos iuris gentium constitutivos y permanentes en aquélla (lo que asemeja la sociedad más al matrimonio romano clásico que a la herencia). Así nos lo reporta Gayo, societas, de qua loquimur, id est quae nudo consensu contrahitur ${ }^{21}$ y Pomponio quien hace una referencia directa al jurista republicano Quintus Mucius Scaevola:

"In omnibus negotiis contrahendis, sive bona fide sint sive non sint, si error aliquis intervenit, ut aliud sentiat puta qui emit aut qui conducit, aliud qui cum his contrahit, nihil valet quod acti sit. Et idem in societate quoque coeunda respondendum est, ut, si dissentiant aliud alio existimante, nihil valet ea societas, quae in consensu consistit ${ }^{22}$.

El nudo consentimiento permanente como elemento constitutivo ${ }^{23}$, el mero disenso como elemento extintivo $^{24}$, la protección jurisdiccional de la buena fe por el pretor peregrino y el libre juego del comercio internacional posibilitaron la participación de ciudadanos romanos y hombres de otras nacionalidades en la constitución de los nuevos contratos de sociedad (in tuitu personae) ${ }^{25}$. Del mismo modo, esta flexibilidad contractual que ofrecía el consensus iuris gentium ${ }^{26}$, que se podía expresar con palabras o por medio de mensajero ${ }^{27}$, propició que los contrayentes moldeasen el contrato a sus intereses convergentes y a finalidades lícitas comunes. La rica actividad empresarial y mercantil, terrestre y marítima que desarrolla Roma desde los últimos siglos republicanos y que explosiona en el Imperio generó innumerables contratos de sociedades con distintas finalidades ${ }^{28}$. Circunstancia que dio lugar a la clasificación escolástica sobre los tipos de sociedades que nos reporta la jurisprudencia clásica. Así Gayo sostiene que "societatem coire solemos aut totorum bonorum aut unus alicuis negotii, veluti mancipiorum emendorum aut vendendorum ${ }^{29 ”}$. En sintonía, Ulpiano, en los comentarios al libro XXXI del edicto del pretor, reporta: "Societates contrahuntur sive universorum bonorum sive

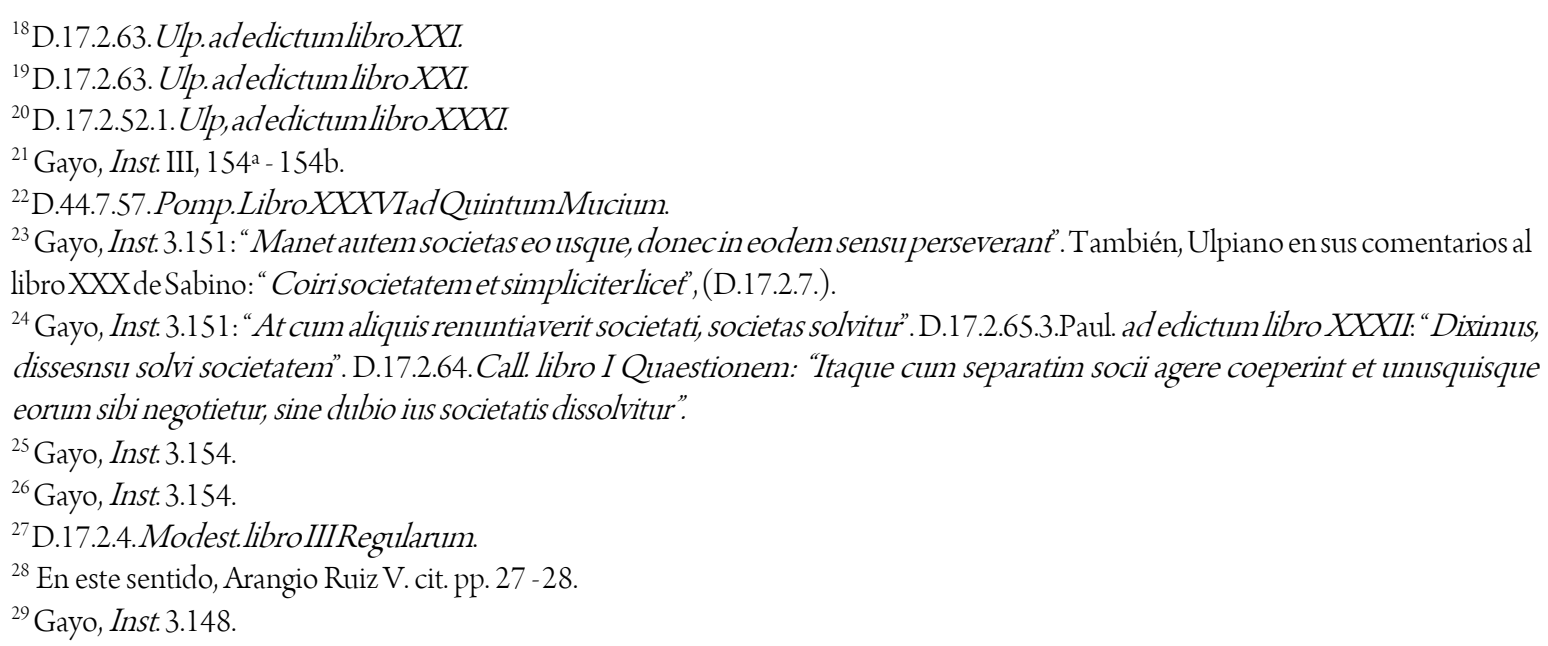


negotiationis alicuius sive vectigalis sive etiam rei unius ${ }^{30 ”}$. Los socios pueden constituir sociedades para todos sus bienes ("In societate omnium bonorum omnes res quae coeuntium sunt continuo communicantur"31), para un negocio (comprar, vender, etc.), para recaudar impuestos del Estado romano, e incluso para una cosa determinada.

Por otra parte, desde el punto de vista de su duración, Paulo en el libro XXXII de sus comentarios al edicto sostiene que: "Societas coiri potest vel in perpetuum, id est dum vivunt, vel ad tempus vel ex tempore vel

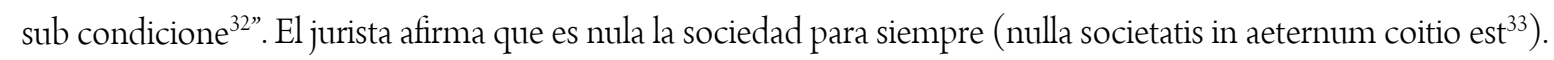
La sociedad puede ser constituida para y de desde un plazo de tiempo, bajo condición, pero no puede durar más tiempo que la vida de los socios que la componen: "Morte unius societas dissolvitur, etsi consensu omnium coita sit, plures vero supersint, nisi in coeunda societate aliter convenerit" ${ }^{34}$. En consecuencia, "societas quemadmodum ad heredes socii non transit ${ }^{35}$.

Los socios negocian directamente, o mediante procuradores mandatarios, en nombre de la sociedad con los terceros (no existió una representación directa, "Agency", en la Roma clásica). De esta forma se incrementan o disminuyen mediante las ganancias o las pérdidas la caja común, constituida inicialmente mediante diferentes aportaciones sociales (en dinero o trabajo ${ }^{36}$ ). Desde la óptica de la responsabilidad de la sociedad frente a terceros, son los socios quienes, aún gozando del beneficium competentiae ${ }^{37}$, responden personalmente frente a las deudas contraídas. Las deudas de la sociedad son las deudas de los socios, quienes se comunican entre sí las obligaciones personales.

Es por ello que, la sociedad clásica no tuvo relevancia externa ni gozó del privilegio de una responsabilidad limitada. Por último, como regla general, tampoco fue concebida por la jurisprudencia como un ente personificado, o al menos, con la posibilidad de ejercer derechos de los que gozasen los ciudadanos y, aún menos, responder de obligaciones como ente jurídico autónomo ${ }^{38}$.

\footnotetext{
${ }^{30}$ D.17.2.5. Ulpianus libro 31 ad edictum.

${ }^{31}$ D.17.2.1.1. Paul.adedictum libro XXXII.

${ }^{32}$ D.17.2.1. Paul. adedictumLibro XXXII.

${ }^{33}$ D.17.2.70. Paul. adedictumLibro XXXII

${ }^{34}$ D.17.2.65.9. Paul.adedictumLibro XXXII.

${ }^{35}$ D.17.2.65.1 1. Paul. adedictum Libro XXXII.D.17.2.63.10.UIp.adedictumlibro XXXI:" Societassolviturexpersonis, exrebus, eX voluntate, ex actione. Ideoque sive homines sive res sive voluntas sive actio interierit, distrahi videtur societas".

${ }^{36}$ Gayo, Inst.3.150.

${ }^{37}$ D. 17.2.63. Ulp. ad edictum Libro XXXI: "Verum est quod Sabino videtur, etiamsi non universorum bonorum socii sunt, sed unius rei, attamen in id quod facere possunt quodve dolo malo fecerint quo minus possint, condemnari oportere. Hoc enim summam rationem habet, cum societas ius quodammodo fraternitatis in se habeat". D.17.2.63.3: "Id quod facere socius potest quemadmodum aestimandum sit? Et placuitnon debere deduciaes alienum quod debeturasocio: ita et Marcelluslibro septimo digestorum scripsit, nisi forte, inquit, ex ipsa societate deleatur".

${ }^{38}$ En este sentido, Zimmermann R. "The Law of Obligations: Roman Foundation of the Civilian Traditor", New York, 1996, pp. 454 - 455. Di Porto A. "Il diritto commerciale romano. Una zona d'ombra nella storiagrafia romanistica e nelle riflessioni storico comparative dei commercialisti', en Nozione formazione e interpretazione del diritto, dall 'età romana alle esperienze moderne, ricerche dedicateal professor Filipo Galo, vol.3, Nápoles 1997,p.419.
} 


\section{EL FENÓMENO EMERGENTE DE LA SOCIETAS PUBLICANORUM}

En los primeros siglos de la República, el Estado romano recurrió a ciudadanos privados para gestionar la recaudación de sus impuestos (vectigales). De ello da cuenta fidedigna Gayo, quien sostiene que los llamados publicanos, es decir, recaudadores de impuestos, gozaban del derecho de tomar en prenda (pignoris capio) y vender mediante subasta los bienes del obligado tributario, constituido en deudor insolvente: "item lege censoria data est pignoris capio publicanis vectigalium publicorum populi Romani adversus eos qui aliqua lege vectigalia deberent ${ }^{39 "}$.

A medida que Roma iba desarrollándose como Ciudad estado, el recurso a los publicani se fue ampliando. Así, otras competencias del Estado se fueron extendiendo a la gestión privada mediante nuevas concesiones, no sólo para la explotación y la obtención de las rentas fiscales de su demanio, suelo agrario (ager vectigalisque $^{40}$ ) y suelo urbano (loci publico ad edificandum ${ }^{41}$ ), sino también para la construcción y el mantenimiento del urbanismo, así como para la prestación de servicios del Populus Romanus: "quae publica uectigalia [aut] ultro tributa ${ }^{42}$.

Posteriormente, con la expansión territorial, fruto de las nuevas oportunidades que ofrecían las conquistas, las subastas públicas periódicas ab hastam se fueron extendiendo también a los nuevos municipios ${ }^{43} \mathrm{y}$ colonias de la península itálica. Las grandes expansiones imperialistas republicanas extra itálicas (iniciadas con las Guerras Púnicas), los intereses públicos y las licitaciones ad hastam del Estado se extendieron tanto al mantenimiento de las guerras como a la colonización y explotación de las nuevas provincias anexionadas, tanto en Occidente (minas de Sicilia ${ }^{44}$, Hispania $^{45}$ ), como en Oriente (Macedonia ${ }^{46}$, Cilicia ${ }^{47}$, Norte de África ${ }^{48}$. Y, según

\footnotetext{
${ }^{39}$ Gayo, Inst.4.28.

${ }^{40}$ Lex Cassia Agraria (486 a C.), Tito Livio, Ab urbe condita, 2.41: "Sp. Cassius deinde et Proculus Verginius consules facti. Cum Hernicisfoedusictum; agripartesduaeademptae. Inde dimidium Latinis, dimidiumplebidiuisurusconsulCassiuserat. Adiciebat huic muneri agri aliquantum, quem publicum possideri a priuatis criminabatur. Id multos quidem patrum, ipsos possessores, periculo rerum suarum terrebat; sed et publica patribus sollicitudo inerat, largitione consulem periculosas libertati opes struere. Tum primum lex agraria promulgata est, numquam deinde usque ad hanc memoriam sine maximis motibus rerum agitata".

${ }^{41}$ Lex Icilia de Aventino Publicando (456 a. C.), Tito Livio3.31: "Deinde M. Valerius Sp. Verginius consules facti. Domiforisque otium fuit; annona propter aquarum intemperiem laboratum est. De Auentino publicando lata lex est".

${ }^{42}$ Tito Livio, Aburbe condita,43.16.2. Cimma MR,, "Ricerche sulle società dipublicani", Milán 1981,pp. 1-40.

${ }^{43}$ D.39.4.13.1. Gayo,LibroXIIIadedictumprovinciale.

${ }^{44}$ CIL.X,80044,1: Mancipiumsulforisprov. Siciliae.

${ }^{45}$ Tito Livio, $A b$ urbe condita, 34.21 nos reporta que Catón estableció grandes impuestos a las minas de hierro y de plata en Hispania, que reportarongrandes réditos a Roma: "pacata provincia vectigaliamagna instituitexferrariisargentariisque quibus tum institutis locupletior in dies provincia fuitt." Es muy probable que la explotación de estas minas fuesen concedidas a la gestión de sociedades de publicanos. En este sentido, Blázquez JM. "Las explotaciones mineras y la romanización de Hispania", en la versión digital del Gabinete de Antigüedades de la Real Academia de la Historia, mantenida por "Antigua: Historia y Arqueología de las civilizaciones", p. 3.

${ }^{46}$ Tito Livio, Aburbe condita, 45.29.3-11.

${ }^{47}$ Cicerón, AdAtt. 6.2.5. Adfam.2.13.2

${ }^{48}$ CIL.VIII, 12377.CTh.4.13.
} 
reporta Cicerón, Asia: "equitibus Romanis, honestissimis viris, adferuntur ex Asia cotidie litterae, quorum magnae res aguntur in vestris vectigalibus exercendis occupatae"49). Romanización que llevaba aparejada una nueva reorganización pública, territorial. Las nuevas estructuras administrativas hicieron surgir, de manera forzosa, la necesidad de licitar nuevas concesiones de obras públicas (vías militares), la prestación de nuevos servicios públicos y la explotación de los recursos demaniales (minas, salinas, ríos, lagos, puertos, etc.) en cada territorio conquistado. En las nuevas anexiones era una exigencia de Estado la explotación tributaria. Esta última tenía como nuevos hechos imponibles, además del suelo, las personas y las mercancías (vectigales: portorium, capitatio, etc.). Cada conquista era aprovechada por Roma para crear una administración fiscal y financiera, que actuaba en beneficio directo del Aerarium Senatorial (en la República) y, posteriormente, del Fiscus Cesaris (ya en el Imperio).

Desde los primeros siglos hasta el final del Imperio de Occidente (su presencia se constata todavía bajo el gobierno de Alejandro Severo (CIL. XIII, 1811), e, incluso, en el Bajo Imperio (CTh., 4.13, De vectigalibus et commissis, 429d.C. - 438 d. C.), los publicanos fueron compañeros y partícipes forzosos no sólo de los avatares políticos y del devenir histórico del Estado Romano, sino también de sus empresas y negocios. Los intereses y las ganancias de los publicanos y sus sociedades siempre estuvieron ligados a los intereses y las ganancias del Populus Romanus. Del logro o no, por este último, de los objetivos públicos, políticos, económicos, e, incluso, imperialistas, dependía siempre la consecución de beneficios privados poraquéllos.

Bajo la vigilancia atenta del Senado ${ }^{50}, y$, generalmente, a propuesta de los cónsules ${ }^{51}$, de los pretores ${ }^{52}$, e incluso de los tribunos ${ }^{53}$, los censores recurrían a la contratación de la gestión privada de las competencias públicas exclusivas del Estado. Para ello, los censores ${ }^{54}$ licitaban concesiones públicas temporales, otorgadas mediante subastas, que garantizaban la igualdad de condiciones de los licitadores (leges censoriae ${ }^{55}$ ) por un plazo de tres a cinco años ${ }^{56}$. Plazo, que, en algunas ocasiones, podía ser a perpetuidad ${ }^{57}$. Su fin: la explotación de un negocio público o una competencia del Estado en régimen privado ${ }^{58}$ (leges locationes).

\footnotetext{
${ }^{49}$ Cicerón, ProLege Manilia, 2.4.

${ }^{50}$ Tito Livio, Aburbe condita, 23.48 - 43.16.2.

${ }^{51}$ LexPortorii Asiae, 46.

${ }^{52}$ Tito Livio, Aburbe condita, 23.48.

${ }^{53}$ Tito Livio, Aburbe condita, 43.16.2.

${ }^{54}$ D.39.4.15. Alf. Var.Libro VIIDisgestorum: “Censor, quuminsulae Cretaecotoriaslocaretlegemitadiserat( ... )”.

${ }^{55}$ Tito Livio, Aburbecondita, 43.16.2. Gayo, Inst.4.28. D.39.4.9. Paul. libro VSententiarum.

${ }^{56}$ Tito Livio, $A$ b urbe condita, 43.16.2, liga la vigencia de los contratos al periodo de tiempo del ejercicio de la censura.

${ }^{57}$ Gayo, Inst.3.145. D.6.3.1. Paul. libro XXIad edictum. "Agri civitatium alii vectigales vocantur, alii non. Vectigales vocantur qui in perpetuum locantur, id est hac lege, ut tamdiu pro his vectigal pendatur, quamdiu neque ipsis, qui conduxerint, neque his, qui in locum eorum successerunt, auferri eos liceat: non vectigales sunt, qui ita colendi dantur, ut privatim agros nostros colendos dare solemos"
}

${ }^{58}$ D.6.3.1.1. Paul.libro XXIadedictum. 
De este modo, aunque posibles discrepancias del arrendamiento se pudiesen dirimir en los tribunales privados, mediante la jurisdicción ordinaria, sin embargo, los ciudadanos y las sociedades se hacían beneficiarios de una concesión pública ab hastam del Estado, o de sus entes territoriales (Qui IIvir iure dicundo praeerit, vectigalia ultroque tributa, sive quid aliut communi nomine municipum eiius municipi locari oportebit, locato ${ }^{59}$ ). Los adjudicatarios siempre quedaban sujetos y sometidos al pliego de condiciones de la subasta. Cláusulas administrativas y fiscales que eran impuestas unilateralmente por el Estado y sus entes territoriales (= Lex Malacitana: Quasque locationes fecerit quasque leges dixerit, quanti quit locatum sit $\left.^{60}\right)$. Contrato privado impuesto en régimen de superioridad, o imperium (leges censoriae - leges locationes ${ }^{61}$ ).

La vinculación al Derecho Público de estas sociedades se ponía de relieve por la vigilancia que ejercían los magistrados sobre el cumplimiento de las causas de incompatibilidad y de las causas de idoneidad para contratar, que se venían estableciendo desde los últimos siglos de la república, por el Estado romano y sus entes municipales. Los magistrados exigían que los socios y sus garantes fuesen compatibles (decurio etiam suae civitatis vectigalia exercere prohibetur ${ }^{62}$ ) y solventes e idóneos (si fideiussores idoneos et cautionem is qui licitatione vicerit offerre paratus $\left.\mathrm{sit}^{63}\right)$. En este sentido, Paulo sostiene que los deudores del fisco no eran idóneos y, por ello, no podín acceder a las subastas ab hastam y eran excluidos de los contratos públicos ${ }^{64}$ : Debitores fisci itemque rei publicae vectigalia conducere prohibentur ${ }^{65}$.

Además, el control de los magistrados sobre las sociedades de rentas públicas se ponía de manifiesto con la posibilidad de ordenar un rescate anticipado de la concesión. Incluso, con el recurso a la fuerza, aquéllos tenían la facultad de ordenar, mediante decreto, el comiso de los bienes de la corporación societaria ${ }^{66}$.

Desde la óptica de la responsabilidad fiscal patrimonial, el Estado vinculaba al manceps y a sus garantes al pago adelantado de las obras públicas licitadas. En otras ocasiones, aquél exigía por anticipado el pago de tributos o vectigales futuros. Ambos casos suponían un traslado del riesgo del negocio del Estado a la responsabilidad personal ilimitada de aquéllos: "cum enim, inquiunt, professiones recitantur, commissum cessat, cum poterit satisfieri fisco ex bonis publicanorum vel fideiussorum ${ }^{67 ”}$. El manceps y los socios publicanos debían prestar, personalmente o bien mediante la participación de terceros avalistas, promesas de cauciones y fianzas, tanto personales (sponsio, fideiussio $=$ Fest. s.v. manceps) como reales (praedes $=$ Lex Agraria 1.46. Fest. s.v

\footnotetext{
${ }^{59}$ LexMunicipii Malacitani, LXIII.(82-84d.C.).

${ }^{60}$ LexMunicipii Malacitani, LXIII. (82-84d.C.).

${ }^{61}$ D.39.4.15. Alf. Var. Libro VII Disgestorum.

${ }^{62}$ D.50.2.6.2. Pap. Libro primo Responsorum.

${ }^{63}$ D.39.4.9. Paul.Libro VSententiarum.

${ }^{64}$ D. 39.4.9.2. Paul. Libro V Sententiarum: "Reliquatores vectigalium ad iterandam conductionem, antequam superiori conductioni satisfaciant, admittendi non sunt".

${ }^{65}$ D.39.4.9.3. Paul.Libro VSententiarum

${ }^{66}$ D.39.4. Depublicanisetvectigalibusetcommissis.D.39.4.16.12. Mar.LibrosingularideDelatoribus. CTh.4.13.

${ }^{67}$ D.39.4.16.12, Marciano, Liber Singulari de Delatoribus.
} vol.09, nº. 02, Rio de Janeiro, 2016.pp. 1075-1119 
manceps. Pseudo Asconio, ad Cic. Div. In Q. Caec 33 (pg. 33 Or.)). Estas garantías cubren al fisco del Estado Romano y a sus entes territoriales los posibles riesgos de insolvencia fiscal que podían surgir de la explotación de la concesión administrativa que aquellos otorgaban individualmente a cada sociedad corporación ${ }^{68}$. En los supuestos de insolvencia tributaria, por quiebra o bancarrota, el Fisco romano subyuga a los deudores personales, obligados por los pagos tributarios (manceps, directivos, praedes, cognitores, fideiussores, etc) a sujetarse al proceso de venta en pública subasta, previsto en la leges praedatoriae. Este procedimiento ejecutivo frente a los socios publicanos y sus avalistas insolventes era prácticamente idéntico en los municipios:

"Eiius municipii item obligati obligata que sunto, uti ii eave populo Romano obligati obli|gatave essent, si aput eos, qui Romae aerario praessent, ii praedes iique cognitores facti eaque praedia subdita subsignata obligatave essent. ( ... ) dum eam legem is rebus vendundis dicant, quam legem eos, qui Romae aerario praeerunt, e lege praediatoria praedibus praedisque vendundis dicere oporteret, aut si lege praediatoria emptorem non inveniet, quam legem in vacuom vendendis dicere oporteret; et dum ita legem dicant, uti pecuniam in fore municipi Flavi Malacitani referatur luatur solvatur. Quaeque lex ita dicta erit, iusta rataque esto ${ }^{69}$.

$\mathrm{Ab}$ initio, los recaudadores de impuestos fueron los publicanos por excelencia. Con el paso del tiempo, todos los beneficiarios de concesiones administrativas y tributarias públicas fueron llamados publicanos. Siempre, en estos casos, estos últimos gozaban del beneficio de lo público, es decir, de la posibilidad de ejercer y explotar industrialmente un sector productivo, o bien prestar un servicio público, en régimen privado. Los empresarios publicanos eran beneficiarios de una auténtica delegación de competencias, de los negocios y de los intereses del Estado Romano (= vectigalia exercere $\left.{ }^{70}\right)$. Así lo cree Ulpiano, quien sostiene que "Publicani autem sunt, qui publico fruuntur (nam inde nomen habent), sive fisco vectigal pendant vel tributum consequantur: et omnes, qui quod a fisco conducunt, recte appellantur publicani ${ }^{71}$.

\section{La adopción de la sociedad por los publicanos}

Durante los últimos siglos de la República, la práctica reiterada y periódica del Estado romano de licitar la explotación de los servicios públicos, la construcción de obras públicas, la explotación del dominio público y la recaudación de impuestos en Roma y la península itálica se trasladó y multiplicó en los nuevos territorios provinciales conquistados. La expansión colonial a gran escala espoleó nuevas actividades de explotación e intereses de Estado. Además, aquélla generó nuevas oportunidades de negocio, despertó el interés ecónomico de los ciudadanos, e incrementó, con gran intensidad, la demanda financiera y empresarial privada. Este escenario condujo a los hombres de negocios de Roma y de sus provincias, bien de modo individual, bien unidos en

\footnotetext{
${ }^{68}$ D.39.4.16.12, Marciano, Liber Singulari de Delatoribus.

${ }^{69}$ LexMunicipii Malacitani,LXIII.(82-84d.C.).

${ }^{70}$ D.50.2.6.Pap.Libroprimoresponsorum.Cicerón, ProlegeManilia,2.4: "investrisvectigalibusexercendisoccupatae”.

${ }^{71}$ D.39.4.1.1. Ulp.Libro55adedictum.
} _vol.09, nº. 02, Rio de Janeiro, 2016.pp. 1075-1119 
sociedad, a participar en numerosas y sucesivas subastas de explotación de competencias públicas que se venían generando y multiplicando en nombre del Populus, no sólo en Roma sino también en sus colonias y municipios. Es por ello por lo que, sin duda, en este contexto histórico, jurídico y macroeconómico es donde se debe situar el fenómeno emergente de las societates publicanorum ${ }^{72}$.

Por el jurista Gayo sabemos que, desde los primeros siglos de la República, los ciudadanos romanos pudieron constituir sociedades entre extraños mediante el recurso a una legis actio certa. Posteriormente, en los últimos siglos de aquélla, este tipo de sociedad es abandonada. Ahora, es posible para los ciudadanos romanos la adopción del contrato consensual iuris gentium. La constitución de estas nuevas sociedades consensuales se hizo extensiva también a los provinciales y a otras personas que, incluso, no gozaban de la ciudadanía romana. A este factor jurídico ayudó un nuevo elemento económico: la introducción de la moneda acuñada en Roma (mitad siglo III a. C. aprox.). Acontecimiento que revolucionó la economía romana y que, además, posibilitó el nacimiento y el desarrollo de nuevos mercados privados de capital financiero. Estos últimos crearon un caldo de cultivo para la constitución de numerosas sociedades de publicanos y posibilitaron su participación activa en los nuevos intereses públicos que fueron surgiendo con la expansión y la colonizaciónimperial.

Así, por lo que respecta a la societas (para V. Arangio Ruiz fueron los primeros ${ }^{73}$ ), los publicanos la adoptaron como un instrumento jurídico de unión permanente y de financiación permanente capitalista para la obtención de beneficios. Las societates publicanorum fueron unas de las primeras clases de sociedades capitalistas con fines lucrativos de la historia económica de Roma. Su constitución, como grandes sociedades de capital financiero privado, las permitió liderar los negocios públicos en unión permanente y simbiosis con el Estado. Esta posición de liderazgo las otorgaba ventaja sobre otras sociedades privadas menos solventes y otros ciudadanos individuales que eran competidores en las grandes subastas públicas. También permitía a las grandes corporaciones conseguir contratos públicos de cuantías económicas muy elevadas, y la adjudicación, a veces sucesiva (portorium autem scrpturam eadem societas habebat ${ }^{74}$ ) de variadas concesiones de explotación, así como la prestación de servicios y la recaudación de impuestos y tasas del Pueblo Romano. Es evidente, que estas sociedades eran privadas, pero en su constitución y funcionamiento debían ser reguladas y vigiladas por el Estado. La adquisición de las concesiones hacía partícipes a las corporaciones de la suerte que corriesen los intereses políticos, los sectores económicos estratégicos y los intereses de Estado. En cierto modo, la vida y la suerte de las sociedades de publicanos siempre estuvieron ligadas a la propia vida del Estado Romano. Incluso, la vida y la

\footnotetext{
${ }^{72}$ En este sentido, Torrent A., "Anulación por el Senado de Locationes Censoriae de Vectigaliay Ultro Tributaen el 184 a. C. (LIV. 39.44.7-8)”, en TeoriaeStoria delDiritto Privato(revistainternazionaleonline) no7,(2014),pp.6-9.

${ }^{73}$ Arangio Ruiz V. cit.p.28.

${ }^{74}$ Cicerón, In Verrem.2.2.71-72.
} 
suerte del Estado, como nos reporta Tito Livio (Guerras Púnicas, 215 a. C., Aníbal en Capua), estuvieron ligadas a la vida y la suerte de la sociedad de publicanos: "Itaque nisi staretur, rem publicam opibus non staturam 75 ".

\section{El problema de la personalidad jurídica de la societas publicanorum: permisum est -ad exemplum Rei Publicae}

Las sociedades de publicanos participaron activamente en casi todos los sectores neurálgicos y estratégicos del Estado. En la obra civil fueron promotores de la edificación y la reparación de obras públicas ${ }^{76}$ (templos, baños públicos, acueductos, vías etc.). Los publicanos construyeron y explotaron el gran demanio del Estado. Así la explotación de minas ${ }^{77}$ (oro, plata, plomo, mercurio, etc.) de salinas y recursos de los ríos, $\operatorname{lagos}^{78}$ y explotaciones de fundos marinos. Desde el punto de vista del crédito, participaron en la acuñación de moneda y la financiación del Tesoro ${ }^{79}$. Intervinieron en la provisión de logística a las legiones ${ }^{80}$ y el abastecimiento de los graneros de Roma ${ }^{81}$. Además, prestaron servicios en el nombre del Estado, como el transporte de bienes públicos y el mantenimiento de un servicio de correos regular en los territorios del Imperio. Las sociedades también promovieron la celebración de juegos y espectáculos circenses, fastos y ceremonias religiosas ${ }^{82}$. Su actividad por excelencia (les dio origen) fue la explotación de la recaudación de los Tributos del Estado (impuestos de explotación del ager vectigalisque, tasas de explotación y construcción del suelo público superficiario, tasas portuarias, tasas arancelarias, tasas fronterizas terrestres, impuestos de sucesiones, etc.).

Su actividad fue vital para el Estado. Por ello, las sociedades de publicanos debían ser privilegiadas por aquél. Sobre todo, las que operaban a gran escala, incluso trasnacional, acompañando a los intereses políticos y económicos del Imperio. La propia naturaleza de estas actividades públicas, que se apartaba de la mera explotación y negociación de las mercancías entre privados (commercium), hizo adquirir un poder político y económico inmenso a los socios publicanos. Poder que se podía tornar frente a los propios intereses del Estado.

\footnotetext{
${ }^{75}$ Tito Livio, Aburbe condita, 23.48.

${ }^{76}$ Valerio Máximo, Facta et Dicta Memorabilia, 5.6.8.: "Age, ut a singulis ad uniuersos transgrediar, quanto et quam aequaliamore patriae tota ciuitas flagrauit! nam cum secundo Punico bello exhaustum aerarium ne deorum quidem cultui sufficeret, publicani ultro aditos censores hortati sunt ut omnia sic locarent, tamquam res publica pecunia abundaret, seque praestaturos cuncta nec ullumassemnisibelloconfectopetiturospollicitisunt",(214a.C.).

${ }^{77}$ D.3.4.1, GaiusadedictumprovincialelibroIII.

${ }^{78}$ D. 43.14.1.7, Ulp. Libro LXVIII ad edictum: "Publicano plane, qui lacum vel stagnum conduxit, si piscari prohibeatur, utile interdictum competeresabinusconsentit:etita Labeo. Ergoetsiamunicipibusconductum habeat, aequissimumeritobvectigalis favorem interdicto eum tuer".

${ }^{79}$ Tito Livio, $A b$ urbe condita, 23.48. Valerio Máximo, Facta et Dicta Memorabilia, 5.6.8: "Age, ut a singulis ad uniuersos transgrediar, quanto et quamaequali amore patriae tota ciuitasflagrauit!nam cum secundo Punico bello exhaustum aerariumne deorum quidem cultuisufficeret, publicani ultro aditos censores hortatisunt ut omnia siclocarent, tamquam res publica pecunia abundaret, seque praestaturos cuncta nec ullum assem nisi bello confecto petituros polliciti sunt', (214 a. C.).

${ }^{80}$ Tito Livio, Aburbe condita, 23.48.

${ }^{81}$ Cicerón, Domus, 10.25.

${ }^{82}$ Valerio Máximo, Factaet Dicta Memorabilia, 5.6.8
} 
Por ello, estas sociedades fueron siempre vigiladas por los poderes públicos. Las sociedades de publicanos se constituyeron como sociedades capitalistas de gestión privada, pero moldeadas, ligadas y sujetas al control fiscal público. De este modo, las sociedades que alcanzaban el estatus de corporación tenían el privilegio de gozar de limitación de responsabilidad frente a terceros. Sin embargo, la responsabilidad de los socios y directivos que se obligaban ex causa fiscalis, mediante los contratos (leges locationes) ab hastam, era ilimitada, y quedaban subyugados ex lege praediatoria. En ocasiones, incluso la vida de la República llegó a quedar al albur del éxito de su gestión. Su participación en la cobertura de las grandes necesidades de financiación del Tesoro, como el sostén de las guerras del Estado frente a poderosos enemigos exteriores, así como la garantía de la provisión de alimentos desde diferentes partes del Imperio a la metrópoli de Roma ${ }^{83}$ crearon situaciones de riesgo y dependencia al propio Estado. Este matrimonio del Estado romano con la sociedad y la empresa privada se apartó del régimen jurídico clásico del contrato de sociedad. Es evidente que las sociedades de publicanos se rigieron por reglas específicas del Derecho privado y por reglas del Derecho público. Esta subordinación jurídica se puso de relieve en la vida de las corporaciones de publicanos. Pues, aunque su estructura y régimen jurídico eran societarios, aquéllas estaban siempre vinculadas a las concesiones administrativas fiscales que conseguían del Estado, o de sus entes públicos territoriales. Precisamente, si creemos a Tácito, este nexo permanente de las societates publicanorum al Derecho público y al gobierno de los magistrados fue advertida por los senadores a Nerón ("plerasque vectigalium societates a consulibus et tribunis plebeis constitutas acri etiam tum populi Romanilibertate $\left.{ }^{84 "}\right)$.

La dependencia de las societates privadas del vectigal público fue una de las grandes bazas que siempre tuvieron los poderes públicos romanos para controlar a aquéllas. Los magistrados podían dificultar las condiciones de la contratación a algunas de ellas, impedir su presentación en las subastas para no renovar la concesión administrativa, pudiendo llegar al rescate, e incluso a la confiscación de toda la concesión mediante un decreto de comiso ${ }^{85}$, que, según Papiniano ${ }^{86}$ y Ulpiano ${ }^{87}$, podía alcanzar a los herederos de los directivos y socios de la corporación ${ }^{88}$.

Normas del Derecho público que, en último término, permitieron y forzaron la transformación de su naturaleza jurídica. Esta, a priori parece ser la solución adoptada por el ordenamiento romano. En este sentido Gayo sostiene que:

"Neque societas neque collegium neque huiusmodi corpus passim omnibus habere conceditur: nam et legibus et senatus consultis et principalibus constitutionibus ea res coercetur. Paucis admodum in causis concessa sunt huiusmodi corpora: ut ecce vectigalium

\footnotetext{
${ }^{83}$ Cicerón, Domus, 10.25 .

${ }^{84}$ Tácito, Annales, 13.50 .

${ }^{85}$ Tito Livio, Ab urbe condita, 43.16.2. D. 39.4.7.1. Papirius. Iustus libro II de Constitutionibus. D.39.4.8, Pap. Libro XIII

Responsorum. D.39.4.11.2. Paul. Libro VSententiarum. D. 39.4.14. Ulpiano libro VIII Disputationum.

${ }^{86}$ D.39.4.8, Pap.LibroXIIIResponsorum.

${ }^{87}$ D.39.4.14. Ulpianolibro VIIIDisputationum.

${ }^{88}$ D.39.4.14. Ulpianolibro VIIIDisputationum.
} 
publicorum sociis permissum est corpus habere vel aurifodinarum vel argentifodinarum et salinarum. Item collegia Romae certa sunt, quorum corpus senatus consultis atque constitutionibus principalibus confirmatum est, veluti pistorum et quorundam aliorum, et naviculariorum, qui et in provinciis sunt ${ }^{89 "}$.

Según el jurista, existen societates publicanorum a las que el Estado Romano les concede un permiso para transformarse y ostentar el estatus y el título jurídico de corporación. Esto significa que no todas las sociedades de publicanos fueron corporaciones, sino sólo aquellas a las que el Estado se lopermitió.

Además, a tenor del texto de Gayo, parece posible sostener que este permiso fue un acto de naturaleza administrativa pública, es decir, una concesión pública discrecional de privilegio que transformaba a la sociedad consensual en una sociedad - corporación. Parece seguro que la existencia de este permiso parece tener sus antecedentes en la Lex Iulia de Collegiis (probablemente ley de Augusto del VII d. C.) que estableció, tal vez a propuesta de los magistrados ${ }^{90}$ y del propio emperador ${ }^{91}$, la competencia del Senado para aprobar, mediante un Senadoconsulto, esta concesión administrativa privilegiada: "Dis Manibus collegio symphoniaorum qui sacris publicis praest sunt quibus senatus coire convocari cogi permisit e lege Iulia ex auctoritate Augusti ludorum causa $^{92 ”}$.

Por su parte, el jurista Gayo, en sus comentarios al libro tercero del edicto provincial, reporta el contenido del privilegio de la concesión: la creación de una sociedad corporativa (collegii societatis) que se debe diseñar ad exemplum re publicae. La estructura de la corporación societaria es un espejo del Populus Romanus, y, en consecuencia, de sus colonias y municipios:

\footnotetext{
"Quibus autem permissum est corpus habere collegii societatis sive cuiusque alterius eorum nomine, proprium est ad exemplum rei publicae habere res communes, arcam communem et actorem sive syndicum, per quem tamquam in re publica, quod communiter agi fierique oporteat, agatur fiat ${ }^{93}$.
}

La corporación deberá estructurarse a imagen rei publicae y deberá contar con aportaciones al patrimonio común, caja o arca común y un actor, o síndico, que la represente y actúe por ella en los procedimientos judiciales. Su funcionamiento interno debe ser semejante al propio del Estado y el de sus entes territoriales municipales. La concesión (quibus permissum est) dota a la sociedad de publicanos de base institucional y corporativa perpetua a semejanza de los entes públicos (ad exemplum rei publicae). Es por ello, que este reconocimiento jurídico transforma a la sociedad, que deja de ser un ente jurídico meramente consensual, para convertirse en una sociedad - corporación, o colegio societario (corpus habere collegii societatis). Además, la

\footnotetext{
${ }^{89}$ D.3.4.1, GaiusadedictumprovincialelibroIII.

${ }^{90}$ Tácito, Ann. 13.50. Cicerón, Domus, 10.25

${ }^{91}$ Santero J.M, "Aspectos de la política julio-claudia en materia asociativa”, en Estudios sobre la Tabula Siarensis, Sevilla, 1986, pp. $172-174$

${ }^{92}$ CILVI, n.2193.También: C.I.L.XIX.2112.AE.1935.25.

${ }^{93}$ D.3.4.1.1, Gaiusadedictum provincialelibroIII.
} 
concesión otorga a aquélla la estabilidad necesaria para el desarrollo de sus negocios e intereses, pues la permite operar de modo permanente y perpetuo para lograr tanto sus fines lucrativos privados, como la consecución de los fines estratégicos públicos del Estado o del ente concedente. Competencias públicas y privadas a los que la corporación - sociedad de publicanos quedaba sometida y engarzada, mediante la adjudicación sucesiva por subasta de las concesiones administrativas ex lege censoriae. En cierto modo, los intereses de la sociedad corporación eran los intereses del Estado y los intereses del Estado eran los intereses de la sociedad - corporación. Así, según narra Tácito (Annales, 13.50), fruto de una petición de rebaja de las tasas abusivas por el pueblo, los Senadores advirtieron a Nerón que estaba en juego la propia vida del Imperio: "disoluttionum imperii docendo".

Tal vez, ésta fue una de las razones (tal vez la más importante) por las que el Estado romano permitió su diseño jurídico y su funcionamiento privilegiado a su imagen y semejanza. La concesión de Derecho público de la categoría de corpus permitía a la sociedad de publicanos disfrutar de una estabilidad institucional permanente para poder cumplir, mediante su gestión privada, los intereses públicos. En este sentido, Cicerón situó a las sociedades de publicanos en la misma línea jurídica pública que regía para los collegia y los concilios: nulla Romae societas vectigalium, nullum collegium, aut concilium ${ }^{94}$. Los negocios, las empresas y los asuntos públicos del Estado necesitaban, en multitud de ocasiones, para su desarrollo periodos de tiempo superiores a la vida del hombre. Si el Estado romano vivía perpetuamente, las corporaciones de publicanos debían disfrutar del mismo privilegio, transcender al tiempo para cumplir con las competencias y explotar los negocios públicos concedidos por aquél.

En esta dirección, la categoría de sociedad como una corporación privilegiada suponía su reconocimiento por el Estado como un ente jurídico autónomo independiente de los socios miembros que le componían: ut ecce vectigalium publicorum sociis permissum est corpus habere ${ }^{95}$. Esta afirmación de Gayo es contundente, pero también cristalina. Además, una inscripción CIL, XIV.2112 del año 136 d.C. (de la misma época que el jurista) reporta que: Lex collegii, caput ex senatus consultum populi Romani. El término caput es sinónimo de personalidad. La inscripción dice que el Senado Romano otorgó reconocimiento y, tal vez, ya zun estatus de personalidad jurídica caput a la corporación mediante la concesión de una Lex collegii? Acorde con la Lex Julia de Collegiis (VII d.C.), es la inscripción de A.E.1935, 25, ya que ésta ratifica la competencia y el poder jurídico del Senado para supervisar y conceder el estatus de derecho público de corporación: "Collegium fabrum quibus ex senatus consulti coire licet donum dedit".

La estabilidad institucional y perpetua de la sociedad con molde jurídico corporativo ad exemplum rei publicae, junto al reconocimiento de su autonomía (de la que también gozaba el Populus Romanus y sus municipios), permitieron al Estado conceder a las corporaciones otros privilegios. Se trataban de condiciones

\footnotetext{
${ }^{94}$ Cicerón, Sest. 14.32.

${ }^{95}$ D.3.4.1, GaiusadedictumprovincialelibroIII.
} 
jurídicas y económicas atractivas, mediante las que la República pretendía atraer la inversión privada y su financiación, mediante aportaciones capitalistas de muchos círculos financieros de socios y sus adfines, para poder cumplir con sus competencias de gobierno y sus necesidades públicas.

Un privilegio fundamental fue la protección jurídica de las aportaciones dinerarias privadas de los socios y de sus adfines a la caja social corporativa. Esta cobertura se consiguió dotando a los entes corporativos societarios de publicanos de responsabilidad personal limitada frente a terceros. Las deudas del ente societario eran independientes de las deudas individuales de sus socios. El ente societario corporativo tiene un patrimonio común que responde limitadamente de las deudas contraídas con terceros. El privilegio consistía en separar la responsabilidad personal del patrimonio privado de los socios de la responsabilidad personal de la corporación asociativa, que estaba ligada a sus aportaciones o cuotas sociales en la corporación. De este modo, la corporación societaria garantizaba el anonimato de su masa social capitalista. Estos privilegios, de los que carecía la societas consensual alicuis negotiationis, de carácter mercantil entre privados, posibilitaron a este tipo de corporaciones contar con sus estructuras empresariales e industriales jerarquizadas para operar en Italia y el Imperio.

\section{Diseño y estructura empresarial de las Societates Publicanorum}

Ya en los últimos siglos de la República, en paralelo con la actividad de expansión y romanización del Estado, las societates publicanorum se constituyeron en auténticas empresas corporativas transnacionales privadas al servicio de aquél y sus nuevas colonias y municipios. Sus intereses siempre permanecían unidos. Si creemos a Marcos Vitruvio, la sociedad corporativa podía tener su sede central en Roma y extender sus delegaciones filiales para el desarrollo de la explotación y gestión en Italia y en las provincias:

"Quae autem in Ephesorum metallis fuerunt officinae, nunc traiectae sunt ideo Romam, quod id genus venae postea est invectum in Hispaniae regionibus, quibus metallis glaebae portantur et per publicanos Romae curantur. Eae autem officinae sunt inter aedem Florae et Quirini96".

De este modo, la estructura empresarial interna de la sociedad - corporación, como ente, era también diferente de la societas alicuius negotiationis consensual, que necesitaba estructurarse externamente mediante el recurso a siervos y peculios para desarrollar su gestión comercial e industrial. Si la sociedad de publicanos gozaba como ente corporativo de responsabilidad limitada, la societas consensual iuris gentium utilizaba a la empresa comercial peculiar para conseguir la limitación de responsabilidad de los socios. Es decir, en la societas publicanorum es el ente el que goza de limitación de responsabilidad, frente a la societas alicuis negotiationis que no la tiene, y, que sólo la puede conseguir con el recurso a la constitución de empresas industriales y comerciales

\footnotetext{
${ }^{96}$ Vitruvio, De architectura, 7.9.4.
} 
peculiares gestionadas por directivos esclavos e hijos sometidos a potestad. Son las empresas peculiares e industriales, no la societas, las que gozaban de este privilegio (dumtaxat de peculio ${ }^{97}$ ).

Generalmente, el ente corporativo diseñaba su estructura empresarial de forma jerárquica y piramidal. A tal fin contaban con el recurso de un presidente, o director ejecutivo, bien de un redemptor ${ }^{98}$ (adjudicatario ab hastam de obras públicas), bien de un manceps (qui quid a populo emit conductive, quia manu sublata significat se auctorem emptionis ess ${ }^{99}$ ). Estos directivos y presidentes fueron los únicos líderes legitimados para vincular jurídicamente a sus corporaciones a las leges censoriae, es decir, a los contratos públicos licitados por el Estado, o sus entes municipales.

El manceps, supremo dirigente de la societas publicanorum, fue homologado por Cicerón a la figura de un praes (nullius rei neque praes neque manceps ${ }^{100}$ ). Así, manceps deriva de mancupium ${ }^{101}$, es decir, de mancipium ${ }^{102}$ que, aunque simbólicamente es coger la cosa con la mano, o bien levantar la mano en una subasta, técnicamente es el poder de someter o crear un nexus jurídico ${ }^{103}$. Esta función jurídica originaria del manceps se extendió progresivamente a otros licitadores y contratistas públicos, esto es, al redemptor y al praes. Todos fueron gestores supremos de sus empresas y sociedades, aunque tuteladas por los poderes públicos (su régimen jurídico y su vida dependen del Estado). Estos directivos fueron asesorados, además, por actores o síndicos, quienes asumían la defensa procesal de la corporación social. Además, en algunas ocasiones, estos líderes de la corporación social situaban a un magister o varios magistrii al frente de las actividades industriales y de la explotación privada de la competencia pública adquirida en las subastas. Esta estructura permitía a la corporación operar con varias empresas y en diferentes territorios y sectores a la vez. La estructura se repetía en las delegaciones que la corporación crea en la península itálica y en las provincias. Así el manceps situaba a un promagistri, que hacía las veces de magister o director ejecutivo, al frente de la explotación industrial de la corporación en la delegación territorial itálica o provincial. Si la corporación explotaba diferentes sectores en el mismo territorio (por ejemplo, minas y recaudación de impuestos) el manceps, como director ejecutivo y, al decir de Cicerón, princeps entre sus socios $^{104}$, podía situar a otros promagistri al frente de cada sector asignado. Las actividades materiales de

\footnotetext{
${ }^{97}$ Gayo, Inst. 4, $72^{\mathrm{a}}-74^{\mathrm{a}}$.

${ }^{98}$ Cicerón, Verr. 2.1.150: "Haccondicione, si quis de populo redemptor accessisset, non esset usus, cum die ceteros redemptores exclusisset, tum in eius arbitrium ac potestatem venire nolebant qui sibi ereptam praedam arbitraretur”.

${ }^{99}$ Festo, p. $151 \mathrm{M}=$ p. 137 L, s.v. "Manceps".

${ }^{100}$ Cicerón, Domus, 10.25 .

${ }^{101}$ Plaut. Mos.5.1.42.

${ }^{102}$ Gayo, Inst. 2.15 ss. Id.2.59.Id.2.65.

${ }^{103}$ Cicerón, Par.5.1.35. Id.Att.8.11.4. Id.Mur.2.Id. Top.5. Gayo, Inst.2.27.

${ }^{104}$ Cicerón, ProPlanc. 13.22.PseudoAsconio, Caec.Div.33: princepssocietatispublicanorum.
} _vol.09, nº. 02, Rio de Janeiro, 2016.pp. 1075-1119 
explotación del negocio en cada sector concreto eran realizadas por siervos y hombres libres ${ }^{105}$ que prestaban sus servicios en la organización comercial e industrial (familia publicanorum ${ }^{106}$ ).

Se lograba así la creación de una estructura corporativa y empresarial trasnacional, que imitaba las estructuras públicas del poder republicano (ad exemplum Rei Publicae). Las grandes sociedades de publicanos eran jerarquizadas, y estaban compuestas por una corporación como ente matriz y sus delegaciones como entes filiales territoriales. Se constituían como holdings corporativos, o colectivos de empresas filiales, y empresas filiales de filiales, que eran dependientes de la grandes corporacion matrices. Mediante este diseño económico, las grandes corporaciones de rentas públicas podían tener legítimas pretensiones de imperium financiero e industrial, pues podían dominar simultáneamente uno o varios sectores de explotación y diferentes territorios y naciones.

\section{LA SOCIETAS PUBLICANORUM COMO INSTITUCIÓN GENERADORA DE PARTICIPACIONES (SUJETAS A LAS FLUCTUACIONES DE LOS BENEFICIOS) Y DEUDA CORPORATIVA}

El éxito de las sociedades de publicanos estuvo ligado siempre al logro de la plena realización y la consecución de las diferentes competencias que les eran delegadas por el Estado Romano. La construcción de puentes y acueductos, la explotación de pozos mineros, de los recursos de los ríos y de los lagos, el cuidado y la explotación maderera de los bosques y de los jardines, así como la recaudación de los numerosos impuestos y tasas de un territorio etc. eran competencias exclusivas del Estado romano que éste subastaba ab hastam para transferir su gestión y, en su caso, la explotación a la iniciativa privada de los particulares. Las sociedades de publicanos fueron empresas privadas de negocios públicos. Por ello, es comprensible que su vida dependiese de la periodicidad y del número de concursos que aquéllas lograsen adjudicarse y de la feliz gestión empresarial e industrial de las competencias del Estado que le hubiesen sido conferidas.

La naturaleza de las competencias que debían gestionar estas sociedades exigía inversiones privadas de cantidades multimillonarias de dineros. El Estado romano recurría a estas sociedades porque actuaban no sólo como empresas de gestión, fomento y explotación sino también como entidades crediticias y financieras del Tesoro Público. En efecto, estas sociedades no solo cubrían las necesidades de liquidez circulante a la hacienda del Estado, sino también adelantaban e invertían sus recursos en los medios materiales y humanos necesarios para la construcción gestión y la explotación de obras públicas (vías, puentes, templos). Incluso, estas sociedades pagaban

\footnotetext{
${ }^{105}$ Valerio Máximo, Facta et Dicta Memorabilia, 6.9.8: "AtP. Rupilius non publicanum in Sicilia egit, sed operas publicanis dedit. idem ultimam inopiam suam auctorato sociis officio sustentauit. ab hoc postmodum consule leges uniuersi Siculi acceperunt acerbissimoque praedonum ac fugitiuorum bello li berati sunt. portus ipsos, si quis modo mutis rebus inest sensus, tantam in eodem homine uarietatem status admiratos arbitror: quem enim diurnas capturas exigentem animaduerterant, eundem iura dantem classesque et exercitus regentem uiderunt" (132 a.C.).

${ }^{106}$ D.39.4.1. Ulp.libroLVadedictum.D.39.4.1.1-6. Ulp.libro LVadedictum.
} 
anticipadamente un cupo a tanto alzado de impuestos, tasas y exacciones fiscales que pudiesen exigir posteriormente en el nombre del Estado (vectigales del ager publicus, solarium, portorium, capitatio, decimatio, etc.). El Estado romano evitaba, de este modo, el riesgo de la gestión de sus negocios, posibles colapsos financieros, e incluso la quiebra. La posibilidad de una bancarrota era trasladaba por el Estado a la sociedad de publicanos y, por ende, al ámbito del mercado privado.

Por su parte, la sociedad de publicanos recibía en contraprestación la explotación temporal (en algunas ocasiones, con carácter perpetuo ${ }^{107}$ ) en régimen de monopolio de un servicio, obra o explotación pública. Esta concesión monopolística garantizaba la transferencia de todas las funciones del Estado a la sociedad privada, su protección pública, la garantía de una ejecución pacífica, y la no concurrencia de libres competidores, al menos, durante el tiempo que durase la concesión administrativa de explotación. Esta protección del Estado, a menudo, garantizaba la posibilidad de obtención de abundantes ganancias y réditos a la empresa de publicanos adjudicataria (Qui maximos fructus ex redemptione vectigalium consequuntur ${ }^{108}$ ) De este modo, tanto desde la óptica jurídica como desde la óptica económica, la societas publicanorum siempre fue una corporación privada privilegiada por el poder público. El Populus Romanus necesitaba premiar la inversión financiera privada, es decir proteger el capital financiero destinado a la creación de sociedades - corporaciones ad exemplum rei publicae que gestionasen y explotasen en régimen de privilegio y monopolio, transcendiendo el tiempo, los negocios del Populus Romanus. Este marco jurídico protector que ofrecía el Estado era un aval para la inversión de cantidades millonarias de dinero en las sociedades de publicanos. En este sentido, los socios y sus adfines colocaban su capital y lo ponían a disposición de la caja o arca común de la societas ${ }^{109}$.

Por todo ello, como reconoce R. Zimmermann ${ }^{110}$, es posible que a partir de la República se desarrollase un mercado financiero en Roma. Sin embargo, pensamos que este último se generó y extendió mediante dos ramas: un mercado de cuotas o participaciones de renta variable, que estuvo en las manos de los socios y sus corporaciones, y un mercado de deuda corporativa que fue controlado y estuvo en las manos de sus adfines.

\section{Mercados de deuda corporativa}

Un gran indicador de la existencia efectiva de este mercado, como ya dijimos, es la presencia permanente de adfines. Grupos financieros que se aliaban con los socios en la explotación de las corporaciones de publicanos. Esta tesis puede encontrar apoyo en las Comedias de Plauto. En su obra Trinummus (2.325), los personajes dialogan sobre el riesgo y las pérdidas que surgen de los negocios:

\footnotetext{
${ }^{107}$ Gayo.Inst.3.145.D.39.4.11.1, Paul.Libro VSententiarum.

${ }^{108}$ D.39.4.11.5. Paullibro V Sententiarum.

${ }^{109}$ Plauto, Trinummus, 2.22.55.

${ }^{110}$ Zimmermann R. "The Law of Obligations: Roman Foundations of the Civilian Tradition", South Africa 1991, reimpr. New York, 1996, p. 468.
} 
PHIL. Qui eam perdidit?

publicisne adfinis fuit an maritumis negotiis?

mercaturan, an venales habuit ubi rem perdidit?

L. Nihil istorum.

Si creemos a Plauto, los adfines participaban, sin duda, en las ganancias y las pérdidas de las sociedades privadas que gestionaban negocios públicos. Del texto, se deduce que el adfin era un financiero. Philto pregunta cómo se produjeron las pérdidas. ¿̇ue financiando a las sociedades que se dedicaban a la gestión de negocios públicos, o fue financiando a los negocios marítimos (maritumis negotiis)?. La contraposición entre la participación financiera en ambas clases de negocios (públicos frente a privados) es evidente. Philto hace una segunda pregunta, ¿̇las pérdidas fueron fruto del comercio con mercancías, o mediante la compraventa de esclavos?

Los adfines no eran socios. Adfin significa próximo, aliado y familiar político. Si creemos A Tito Livio, los socios participaban, con el apoyo financiero de sus adfines, en las subastas públicas ad hastam:

"In equitibus recensendis tristis admodum eorum atque aspera censura fuit: multis equos ademerunt. In ea re cum equestrem ordinem offendissent, flammam inuidiae adiecere edicto, quo edixerunt, ne quis eorum, qui Q. Fuluio A. Postumio censoribus publica uectigalia aut ultro tributa conduxissent, ad hastam suam accederet sociusue aut adfinis eius conductionis esset ${ }^{111}$.

Tito Livio distingue dos grupos de poder que participaban, de diferente forma, en los negocios que eran gestionados por las sociedades de publicanos. Por una parte, los socios $y$, por otra, sus adfines (sociusue aut adfinis eius). Los adfines son categorías de personas próximas a las sociedades, pero no forman parte corporativa de las sociedades de publicanos. Los adfines fueron grupos diferentes a los círculos de socios. De este modo, si no eran socios (como testimonia, de modo cristalino, Tito Livio) debemos creer a Plauto, quien los sitúa directamente en la órbita de los negocios públicos (publicisne adfinis fuit ( ... ) negotiis?).

En consecuencia, creemos que los adfines fueron círculos de hombres de negocios que financiaban, mediante préstamos, las cuotas o participaciones proporcionales de los socios. De esta forma, aquéllos se tornaban en aliados de éstos últimos para la protección de sus negocios e intereses económicos. Como dijimos, adfin significa, por excelencia, aliado. Los créditos de los adfines estarían destinados a la adquisición por los socios de sus participaciones, tanto grandes (indivisas) como pequeñas (fraccionadas), del capital social corporativo. Es por ello que, muy probablemente, los adfines pudieron ser, además, agentes de captación de recursos financieros externos, e intermediarios de los socios con otros inversores y hombres de negocios (banqueros y prestamistas). En consecuencia, los adfines fueron probablemente grupos de inversores privados que no gozaban de la condición jurídica de socios, por lo que se unían a uno o varios socios para poder invertir, mediante ellos, en la deuda corporativa de los socios y de la corporación. Cada socio tenía una participación proporcional en el capital social de la corporación. Esta participación proporcional del socio sería la suma de su aportación individual más las

${ }^{111}$ Tito Livio, Aburbe condita, 43.16.2. _vol.09, n. 02, Rio de Janeiro, 2016.pp. 1075-1119 
cantidades financiadas, mediante créditos y, tal vez, depósitos irregulares, por los adfines, quienes, de esta forma, se posicionaban como acreedores de deuda corporativa y como titulares de préstamos financieros. Pero, a su vez, los adfines adquirían un estatus de subordinación y clientela política empresarial frente a sus socios (explica su nombre: adfin).

Las diferentes participaciones de los socios y los créditos de sus adfines constituirían un paquete financiero de la sociedad de publicanos, que estaría compuesto de participaciones o cuotas de renta variable (shares) y de deuda corporativa (bonos). La suma de ambos constituiría, por una parte, un porcentaje global financiero acreedor y por otra, una participación dueña en el capital de la corporación - sociedad.

Los socios y sus adfines debieron constituir auténticos "lobbies". Familias y grupos de presión. Sus actividades eran dirigidas a crear influencias sobre las decisiones y las políticas económicas e industriales que eran diseñadas por los directivos (magistri) y los presidentes de las sociedades corporativas (redemptor, manceps). En este sentido, una Lex Portorii Asiae (Efeso, 75 a. C. - 62 d. C.), llave fiscal del Estado romano que gravaba la navegación, la importación y exportación de mercancías del Imperio con Asia, otorga libertad a los socios publicanos para decidir si prorrogan el mandato de su manceps para la gestión de una nueva concesión, o si, por el contario, deciden sustituirle ${ }^{112}$.

Es evidente que esta facultad demuestra el poder y la gran influencia que ejercían los grupos de socios junto a sus círculos de adfines en los órganos directivos y ejecutivos de sus corporaciones. Como se deduce de las noticias históricas de Tito Livio y de las comedias de Plauto, de los éxitos empresariales de la sociedad dependían directamente tanto las pérdidas como una posible revalorización de las participaciones de los socios. Los repartos de los dividendos de la corporación correrían la misma suerte.

Diferente suerte correría el cobro de los créditos con sus intereses por los adfines. Sus activos financieros eran exigibles y estaban desligados de los beneficios y de los réditos empresariales de la corporación.

Por otra parte, los socios y sus adfines trataron de influir en las decisiones de los magistrados licitadores. Tito Livio narra las presiones que ejercieron aquéllos sobre el tribuno Tiberio Graco (padre de los tribunos Tiberio y Cayo Graco, 184 a.d.C.), para que éste último derogase un edicto de los censores, que había prohibido presentarse a las subastas de recaudación de los impuestos a aquellas sociedades de publicanos que hubiesen sido beneficiarias de estas concesiones durante la censura de Cayo Claudio y Tiberio Sempronio. Fruto de la alianza de los socios con sus adfines y de la presión política que ejercieron, Tiberio Graco anuló el edicto y la prohibición de los censores:

\footnotetext{
${ }^{112}$ LexPortoriiAsiae, 46.
} 
"In equitibus recensendis tristis admodum eorum atque aspera censura fuit: multis equos ademerunt. In ea re cum equestrem ordinem offendissent, flammam inuidiae adiecere edicto, quo edixerunt, ne quis eorum, qui Q. Fuluio A. Postumio censoribus publica uectigalia aut ultro tributa conduxissent, ad hastam suam accederet sociusue aut adfinis eius conductionis esset. Saepe id querendo ueteres publicani cum impetrare nequissent $\mathrm{ab}$ senatu, ut modum potestati censoriae inponerent, tandem tribunum plebis P. Rutilium, ex rei priuatae contentione iratum censoribus, patronum causae nancti sunt. Clientem [eius] libertinum parietem in Sacra uia aduersus aedes publicas demoliri iusserant, quod publico inaedificatus esset. Appellati a priuato tribuni. Cum praeter Rutilium nemo intercederet, censores ad pignera capienda miserunt multamque pro contione priuato dixerunt. Hinc contentione orta cum ueteres publicani se ad tribunum contulissent, rogatio repente sub unius tribuni nomine promulgatur, quae publica uectigalia [aut] ultro tributa C. Claudius et Ti. Sempronius locassent, ea rata locatio ne esset: ab integro locarentur, et ut omnibus redimendi et conducendi promiscue ius esset. Diem ad [eius] rogationem concilio tribunus plebis dixit. Qui postquam uenit ut censores ad dissuadendum processerunt, Graccho dicente silentium fuit; [cum] Claudio obstreperetur, audientiam facere praeconem iussit. Eo facto auocatam a se contionem tribunus questus et in ordinem se coactum ex Capitolio, ubi erat concilium, abit. Postero die ingentis tumultus ciere. Ti. Gracchi primum bona consecrauit, quod in multa pignoribusque eius, qui tribunum appellasset, intercessioni non parendo se in ordinem coegisset; C. Claudio diem dixit, quod contionem ab se auocasset; et utrique censori perduellionem se iudicare pronuntiauit diemque comitiis a C. Sulpicio praetore urbano petit. Non recusantibus censoribus, quominus primo quoque tempore iudicium de se populus faceret, in ante diem octauum et septimum kal. Octobres comitiis perduellionis dicta dies ${ }^{113}$.

Además, Tito Livio constata la existencia de negociaciones directas de los publicanos con el Estado. Mediante aquéllas, estos últimos exigían garantías concretas (cobertura de pérdidas contra tormentas y capturas $^{114}$ ) y el cumplimiento de algunas condiciones (exención del servicio militar ${ }^{15}$ ) en la contratación. Según el testimonio de Tito Livio existieron presiones corporativistas directas de los publicanos al Senado ${ }^{116}$, quienes, incluso, trataron de marcar las directrices políticas y económicas que debía seguir el propio Estado.

Desde la óptica de los socios, Valerio Máximo (73 a. C. aprox.) sostiene que aquéllos también participaban directamente en acciones de chantaje sobre los magistrados para defender sus intereses en la corporación:

"Atque ut nobilitati, beneficio paenitentiae se ipsam admonitae respicere, altiora modo suo
sperare ausos subtexamus, T. Aufidius, cum Asiatici publici exiguam admodum particulam
habuisset, postea totam Asiam proconsulari imperio obtinuit. nec indignati sunt socii eius
parere fascibus, quem aliena tribunalia adulantem uiderant gessit etiam se integerrime atque
splendidissime. quo quidem modo demonstrauit pristinum quaestum suum fortunae,
praesens uero dignitatis incrementum moribus ipsius inputaridebere ${ }^{117}$. Valerio Máximo dice que Tito Aufidio fue propietario de una particula. Posiblemente se trataría de una pequeña subcuota de participación proporcional de renta variable, que nutría a la cuota de participación de alguno de los socios de una corporación de publicanos, que operaba en la provincia de Asia. También es posible que Tito

\footnotetext{
${ }^{113}$ Tito Livio, Aburbe condita, 43.16.2.

${ }^{114}$ Tito Livio, Ab urbe condita, 23.49.

${ }^{115}$ Tito Livio, Ab urbe condita, 23.49.

${ }^{116}$ Tito Livio, Aburbe condita, 43.16.2.

${ }^{117}$ Valerio Máximo, FactorumEtDictorum Memorabilium,6.9.7.
} 
Aufidio fuese un socio pequeño, es decir, un miembro de un grupo más amplio y potente de socios. La alusión directa a los socii que hace el fragmento parece confirmar esta tesis. Valerio Máximo constata también la participación directa de Tito Aufidio en actividades de presión, mediante persuasiones (obviamente como lobby) a los magistrados de Asia (quienes evidentemente licitaban y vigilaban la actividad de la societas publicanorum). También, por Salustio ${ }^{118}$ y Velleio Paterculus ${ }^{119}$ sabemos que los publicanos y otros hombres de negocios denunciaron a Marcos Metello por ralentizar las operaciones de guerra contra Iugurta en el Norte de África durante tres años.

Socii et adfines fueron círculos de presión de las sociedades y corporaciones de publicanos. La participación capitalista directa de numerosos socios en las corporaciones y la intervención financiera (en la sombra) de sus grupos de adfines mediante la inversión crediticia en participaciones o cuotas de renta variable de los socios, hacen aflorar el motivo de su gran interés por proteger sus inversiones. Los socios y sus adfines se juegan su dinero privado en el riesgo de los negocios públicos. La clientela familiar financiera y especuladora de los adfines era guiada por la dirección estratégica de sus socios. Los diferentes grupos de socios y sus círculos capitalistas de adfines trataron de influir continuamente tanto en la dirección y en la gestión de las corporaciones, como las políticas públicas del Estado para salvaguardar, e incluso para aumentar sus intereses. Estos grupos de adfines, que permanecieron unidos por pactos económicos, industriales y comerciales corporativos fueron aliados de uno o varios socios (adfines et socius eius). Simbiosis de intereses que surgieron forzosamente fruto de la concesión de crédito y de la financiación de las participaciones sociales de renta variable. En esta inversión debemos comprender tanto las cuotas sociales (portiones) como las participaciones fraccionadas menores (particulae, como nos reportó Valerio Máximo, 6.9.7.).

Los círculos de adfines constituyeron el mercado de deuda corporativa de las sociedades de publicanos.

Esta afirmación se puede deducir de Polibio 6, 17:

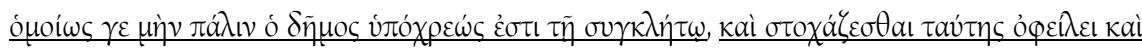

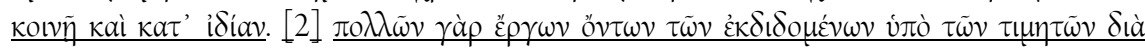

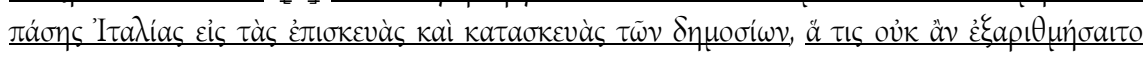

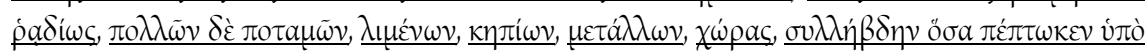

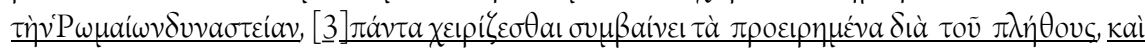

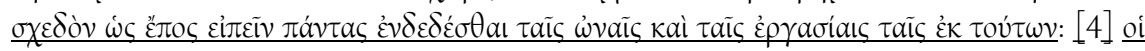

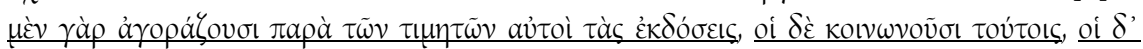

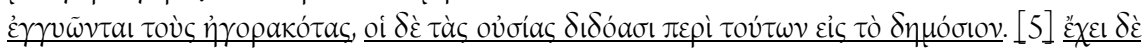

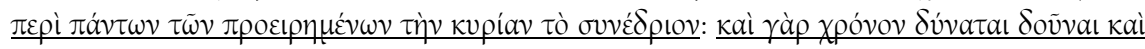

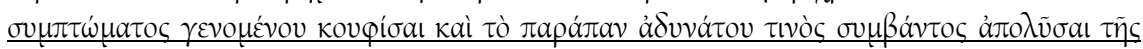

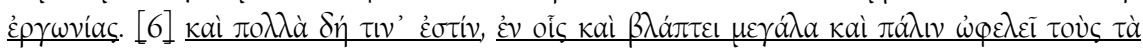

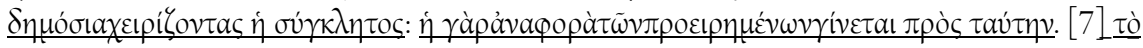

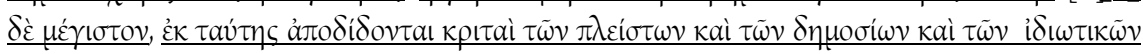

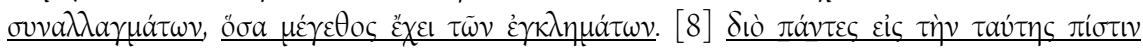

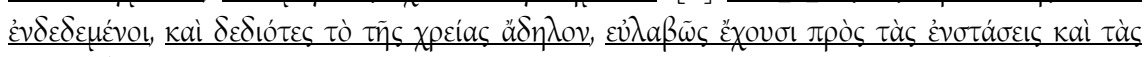

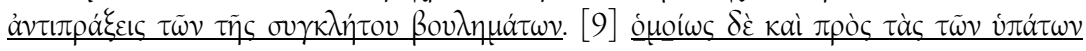

\footnotetext{
${ }^{118}$ Salustio, Iugurta, 65 .

${ }^{119}$ P. Velleio, 2.11.2.
} 


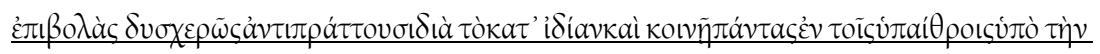

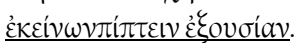

Según Polibio, los censores adjudican muchas obras públicas en toda Italia. Construcción y reparación de obras públicas, explotación del demanio (ríos, puertos, jardines, bosques, mina, campos, etc.). En resumen, todo lo que ha pasado a la dominación romana. Por la naturaleza de los sectores de explotación, creemos, que en algunas ocasiones, las sociedades de publicanos se constituyeron, en la práctica, como Estados dentro del Estado romano (peligro advertido por Augusto, quien procedió a su control y en algunos supuestos a su sustitución). Además, Polibio cree que los contratos públicos licitados en Italia (también en las provincias, fruto de la progresiva romanización) fueron numerosos. Todo el demanio fue susceptible de explotación y fue, además, controlado por el Estado, mediante el Senado. Según Polibio, numerosos concursos públicos son licitados por los censores. Además, el historiador nos dice que prácticamente todos los ciudadanos, dependiendo de sus posibilidades económicas, estaban interesados en participar bien en la inversión y en la gestión de las sociedades privadas de gestión de los negocios públicos (equites y hombres de negocios), bien como familia asalariada prestando trabajos y servicios dentro de la organización industrial y corporativa (plebeyos). Esta noticia es acorde con las informaciones de Cicerón (Pro lege manilia, 2.6) quien sostiene: "aguntur bona multorum civium quibus est a vobis et ipsorum causa et rei publicae consulendum".

En conclusión, tanto para crear nuevas sociedades como, también, para atender a las numerosas y crecientes demandas financieras de las grandes corporaciones societarias, los hombres de negocios (financieros, banqueros, empresarios e industriales) crearon mediante sus transacciones numerosos mercados de crédito para satisfacer la inversión de grandes sumas de capitales. Es por ello que Polibio asegura que muchos ciudadanos estaban interesados e involucrados en estas corporaciones, $y$, por ende, en los mercados de deuda y en los mercados de capital que aquéllas generaban. En esta dirección, el Historiador griego reporta que muchos ciudadanos se presentan como mancipes a las subastas y a la adjudicación de los contratos de los censores. Otros ciudadanos son los socios de aquéllos. Ambas clases de personas son los integrantes y forman parte de la sociedad corporativa de publicanos. Posteriormente, (sigo la interpretación del fragmento 6,17) Polibio sostiene que existen otros ciudadanos que ya no forman parte, ni son dueños, de las sociedades corporativas, pero que, desde el exterior, apoyan financieramente a éstas últimas. Estos ciudadanos prestan seguridad, es decir, son los avalistas de los mancipes ante el fisco, y, por último, los ciudadanos que prestan seguridad, es decir, que avalan a estos últimos, y, por ende a los socios y sus mancipes, prestando sus fortunas como forma de garantía y de cumplimiento de solvencia e idoneidad al Estado. Todo ello era realizado para que las sociedades de publicanos pudiesen operar como corporaciones industriales, cumplir sus obligaciones fiscales frente al Estado, y cumplir su fin por antonomasia: la adquisición de ganancias en nombre delEstado. 
Del texto de Polibio, se pueden extraer algunas conclusiones precisas:

1. La inercia del crecimiento de Roma condujo a una inercia paralela de crecimiento en las corporaciones societarias de publicanos para gestionar los negocios públicos del Estado en Roma y en lasprovincias.

2. La fuerte demanda del Estado, exigiendo el concurso de numerosas sociedades de publicanos, generó la necesidad de la creación espontánea y natural de mercados financieros de capitales para satisfacer las necesidades de aquéllas.

3. Las sociedades de publicanos contaron con el concurso de directivos y socios dueños que aportaron sus capitales a la caja social corporativa. También participaron personas extrañas que no tenían la condición jurídica de socios. Hombres de negocios afines a los directivos, a los socios y a la corporación, que financiaron créditos y prestaron garantías, mediante avales reales y personales, a éstos.

4. Es por ello, que las demandas de dinero de las sociedades de publicanos generaron mercados de deuda corporativa, que era financiada por extraños no dueños y mercados de capital que era financiado por directivos y socios dueños (= objeto de nuestra investigación).

Por estas razones, no parece convincente la tesis de G. Dufour, quien sostiene que "les adfines n' aient en réalité existé que dans les enterprises de publicains qui s'occupant de travaux publics, et non dans celles qui prenaient à farme la perception d' impôts ${ }^{120 "}$.

Antes que un empresario de trabajos públicos, excluido de la recaudación de impuestos, nosotros creemos que el adfin fue un acreedor de la deuda corporativa de una sociedad, o de una empresa de publicanos. El adfin no es socio. No forma parte directa de la sociedad "no share in the management ${ }^{121}$ ". En este sentido, se posiciona P. William Duff quien sostiene, además, que "the same principie may apply to the participes or adfines, who seem to be investors who have lent money to the publicani ${ }^{122}$. Por ello, el adfin no está sujeto a responsabilidad limitada ni ilimitada. Tampoco es un socio comanditario, como cree H. Mitteis ${ }^{123}$ (la sociedad comanditaria es una institución medieval). El adfin es un inversor financiero. Este último proporciona créditos a los socios publicanos mediante depósitos irregulares. Así lo creen H. Mitteis ${ }^{124}$ y M. R. Cimma. Esta última, además, cree: "questa mi sembra l'hipotesi più accettabile, innanzi tutto perchè in questo modo la società avrebbe ricevuto un capitale, del quale avrebbe potuto usare liberamente, rimanendo inttatto il diritto del depositante di

\footnotetext{
${ }^{120}$ Dufour G. "Societates Publicanorum: Existait-il une Borse ou un Réseau de Courtiers sous la République Romaine?", en R.D.U.S (2011), pp. 333 - 334.

${ }^{121}$ William Duff, P., "Personality in Roman Private Law", Cambridge, 1938,pp. 159-160.

${ }^{122}$ William Duff, P., cit. pp. 159-160.

${ }^{123}$ Mitteis H., Romiches Privatrecht, 1908, pp. 413 - 414

${ }^{124}$ Mitteis H., cit.pp. $413-414$.
} 
chiederne la restituzione ${ }^{125 ”}$. Además, según la autora, el depósito irregular fue muy conocido y practicado en la República "a scopi speculativi ${ }^{126 "}$.

Los depósitos irregulares son contratos y no parecen, a priori, ser activos financieros aptos para ser negociados en los mercados de deuda. Así, de acuerdo, con H. Mitteis y M. R Cimma, mediante un depósito irregular la sociedad corporativa puede lograr uns fuente de financiación para su tesorería. Al vencimiento de este contrato, el depositante exige la devolución del capital y los intereses pactados. Desde la óptica de la transferencia del crédito, es posible, que a petición del acreedor, se pudise lograr una delegación de aquél (delegatio), es decir, un cambio de titularidad activa, o de acreedor depositante ${ }^{127}$. Bastaría una simple transferencia del crédito mediante una delegatio crediti. El acreedor (1) podría ordenar a la sociedad de publicanos que pagase a un nuevo acreedor (2) (el acreedor (1) es deudor del nuevo acreedor (2)). Bastaría una stipulatio novatoria y el permiso de la sociedad corporativa. También se pudo lograr el cambio de un sujeto activo por otro mediante una inscripción literal (nominibus transcripticiis). A tal fin, la sociedad corporativa deudora realizaría un simple cambio de acreedor con una nueva anotación literal, nomina transcripticia ${ }^{128}$ en sus libros de contabilidad de partida doble (sociorum tabulas accepti et expensi ${ }^{129}$ ). En este sentido, M.R. Cimma sostiene que "in queste tabulae senza dubbio venivano annotati anche i conferimenti di chi partecipava con capitale senza essere socio". Aunque piensa, además, que no por ello se puede sostener que existiese una relación directa entre la sociedad y losadfines ${ }^{130}$.

Con todo, a pesar de estas ventajas, el depósito es un contrato real, y, por su naturaleza, es una institución financiera estática. El depósito no es un activo apto para circular con fluidez en los mercados secundarios de crédito y de deuda corporativa. Tal vez, los préstamos constituidos mediante contratos verbales de sponsio stipulatio y stipulationes sortis et usurarum respondieron mejor al tráfico del crédito. En este sentido, P. Bonfante cree que "nel periodo dell' espansione mondiale di Roma la classe dei capitalisti romani (e non solo i cavalieri, ma forse in più larga misura i senatori, data la loro legale esclusione dai commerci e dalle industrie), esercitò senza

\footnotetext{
${ }^{125}$ Cimma, MR cit.p. 94

${ }^{126}$ Ibíd. cit.p. 94 .

${ }^{127}$ Rodríguez Ennes L., Daza Martínez J., "Instituciones de Derecho Privado Romano”, Valencia 2009,pp. 321 - 322.

${ }^{128}$ Cicerón. Pro Roscio, 1.12: “... de tuarum tabularum fide compromissum feceris. Gayo Inst. 3, 128. D. 20,1, 26. Mod. Libro IV Responsorum: Pater Seio emancipato filio facile persuasit, ut, quia mutuam quantitatem acciperet a Septicio creditore, chirographum perscriberet sua manu filius eius, quod ipse impeditus esset scribere, sub commemoratione domus ad filium pertinentispignoridandae: quaerebatur, an Seius intercetera bona etiam hancdomumiureoptimopossidere possit, cumpatris se hereditate abstinuerit, necmetuiri ex hocsolo, quodmandante patremanusuaperscripsitinstrumentum chirographi, cumneque consensum suum accomodaverat patri aut signo suo aut alia scriptura. Modestinus respondit: cum sua manu pignori domum suam futuram seius scripserat, consensum ei obligationi dedisse manifestum est".

${ }^{129}$ De la obligación de teneduría de los libros de contabilidad por las sociedades de publicanos nos informa Cicerón, Verr. 2.2.76.186. Cicerón, Verr. 2.2.76.187-77.188; "Quod lege excipiuntur tabulae publicanorum”. Cicerón, Verr. 2.74.182: "Sciebam enim hancmagistrorum, quitabulas haberent, consuetudinem esse, ut quum tabulasnovomagistro traderent, exempla literarum ipsi habere non nollent". Sobre la falsedad y manipulación de los libros de contabilidad de las corporaciones de publicanos (descubiertas porlos magistrados) Tito Livio, Aburbecondita, 13.50: "et quaeexactionibusillicitisnomina publicani invenerant". ${ }^{130}$ Cimma MR, cit, 39, Milán 1981, p.95.
} 
freno la usura nelle province, le quali non erano prottete dalla leggi romane ${ }^{131}$. De esta forma, el acreedor adfin entregaría en concepto de mutuo una cantidad elevada de dinero y la sujetaría al pago de un interés fijo, que sería más o menos elevado en función del peligro que corriese su financiación (riesgo libremente estimado por aquél). Una vez, vencido el plazo del préstamo, el socio con participación en la sociedad, o bien la propia corporación (según quien se haya obligado como deudor) tenían que devolver el capital más los intereses fijos pactados, con independencia de los resultados económicos de la sociedad. En esta dirección, P. Wiiliam Duff va más allá, pues, incluso, cree que el tipo de interés se haría depender de la rentabilidad obtenida por el socio durante el plazo establecido. Según P. William Duff la interrogación y la respuesta estipulatorias de este contrato de crédito verbal serían:

- "Do you promise to pay me whatever interest you receive on the money lent to the gold - mining of Nagy Enyed?"

- "I promisse"132.

P. William Duff sostiene que el adfin no es socio. El adfin se situaría en la condición de partícipe como titular de un préstamo de interés variable. Según la propuesta que plantea P. William Duff, el tipo de interés del crédito fluctuaría. La rentabilidad de este último iría ligada a las ganancias y a los éxitos de la empresa corporativa. Situación que parece situar al adfin en la condición de titular de créditos que generan deuda corporativa.

$\underline{\text { Títulos Valores de deuda corporativa privada de las sociedades de publicanos en los }}$ mercados financieros: chirographa

Como punto de partida, creemos que respondieron mejor a las necesidades financieras de las sociedades de publicanos y de los mercados de deuda privada generados por aquéllas, los instrumentos y activos financieros, muy difundidos en época de Gayo, que hacían nacer las obligaciones literales (obligatio litteris ${ }^{133}$ ). En esta dirección, tal vez, lo más frecuente fue, que una vez realizada la stipulatio creadora del préstamo y entregado el dinero (pecuniae numerata) a la caja de la corporación societaria para perfeccionar el contrato de mutuo ${ }^{134}$, el crédito del adfin se recogiese en un título, o documento literal, llamado chirographa, que permitiría la anotación de aquél como primer acreedor, es decir, mediante su primera inscripción literal en los libros de caja probatorios, nomina arcaira ${ }^{135}$, de los socios publicani ${ }^{136}$.

\footnotetext{
${ }^{131}$ Bonfante P., “Corso di Diritto Romano, vol 4. Le Obbligazioni", 1918 - 1920, reimpresión 1979, p. 404.

${ }^{132}$ William Duff, P., cit.pp. $159-160$.

${ }^{133}$ Gayo, Inst. 3. 89; 3.119a.

${ }^{134}$ Gayo, Inst.3.131: "quiipenonalitervalent, quam sinumeratasitpecunia”.

${ }^{135}$ Gayo, Inst. 3.131 .

${ }^{136}$ Tito Livio, Aburbe condita, 13.50.
} 
La chirographa es un título financiero de reconocimiento de crédito firmado por la mano del propio deudor, con valor probatorio ${ }^{137}$. Cicerón pone de relieve su carácter jurídico (título literal) en su segunda Filípica dirigida a Marco Antonio. Mediante sus invectivas, Cicerón acusa a Marco Antonio de falsificar títulos valores de crédito reconocidos por empresas: "cuius domi quaestuosisima est falsorum commentariorum et chirographorum officina ${ }^{138 ”}$. Este carácter jurídico de la chirographa, como título de crédito literal, hizo de ella un activo de inversión idóneo para su libre circulación por los mercados de capitales y para la realización de los negocios comunes e interconectados del Imperio. En este sentido, se posicionan S. Von Reden ${ }^{139}$, D. Hollander ${ }^{140}$ y G. Astuti ${ }^{141}$, quienes creen que la cesión de créditos fue posible con el endoso de los títulos idóneos. Acaso, este fue uno de los principales motivos de su importación desde las provincias helenísticas y de su recepción por el Derecho civil, en los siglos finales de la República. Este encuentro se tornó en una verdadera adopción jurídica, según cree J.J Aubert ${ }^{142}$, quien sostiene, además, que los instrumentos financieros, chirographa y syngrapha, pasaron a ser considerados como una nueva especie de contratos (literales) que se integraron en las familias romanas de contratos (reales, verbales y consensuales). Y, en consecuencia, este éxito de su incorporación, dóto a estos instrumentos capitalistas de inversión de una eficacia duradera, según cree W.L. Burdick, "they were in daily use in the Roman Business World for many years ${ }^{143}$. Roman Bussines entre los que se incluyen los mercados de capital que financian a las diferentes corporaciones industriales trasnacionales de publicanos ${ }^{144}$.

Los chirographos son activos financieros que ofrecen grandes ventajas y seguridad ${ }^{145}$ a sus tenedores. La exigencia y la rentabilidad de estos instrumentos son independientes de los beneficios obtenidos en cada ejercicio por la sociedad corporativa. En consecuencia, su titular no es necesariamente socio de la corporación.

Por lo que respecta a la configuración del chirographo como instrumento (instrumentum chirographi ${ }^{146}$ ) de crédito financiero (Modestino, Libro IV Responsorum: "quia mutuam quantitatem acciperet a Septicio creditore, chirographum perscriberet sua manu filius eius". Cicerón Fam. 10.21.1: "credidi chirographis eius"), la sociedad corporativa de publicanos, después su primera respuesta estipulatoria constitutiva del préstamo inicial, que la situaba como parte deudora de la obligación contraída, firmaría el título valor de deuda, con carácter

\footnotetext{
${ }^{137}$ Cicerón, Philippica, 2.4 .

${ }^{138}$ Cicerón, Philippica, 2.35.

${ }^{139}$ Reden Von S., “Moneyin classical Antiquity”,Cambridge 2010 pp. 111 - 112.

${ }^{140}$ Hollander D., "Moneyin the Late Republic",New York, 2002, pp. 46 - 47.

${ }^{141}$ G. Astuti, Cesione (premmessa storica), en ED. vol. 6, 1960, p. 805 s. Arangio Ruiz V. “Studi epigrafici e papirologici”. A cura di Lucio Bove, 1974, p. 425 s., sostiene que que los militares romanos también hacían circular libremente el crédito mediante quirographos.

${ }^{142}$ Aubert, J.J., "Commerce”, en The Cambridge Companion to Roman Law, New York, 2015,p.232.

${ }^{143}$ Burdick W.L., "The Principles of Roman Lawand their Relation to Modern Law”, 1938, reimpresión New Jersey 2004, pp. 436 437.

${ }^{144}$ Gayo, Inst.3.134.

${ }^{145}$ Cicerón, Fam.10.21.1 - 2, 13,3.

${ }^{146}$ D.20.1.26.1,Mod.LibroIVResponsorum.
} 
probatorio, y se lo entregaría al financiero acreedor. De este modo, en los supuestos de nuevas y continuadas transmisiones de títulos de crédito entre adfines, éstos recurrirían a la realización verbal de sucesivas stipulationes novatorias, dirigidas tanto a cambiar el sujeto activo, sin necesidad de pedir permiso a la sociedad corporativa, como al consiguiente endoso de la chirographa al nuevo acreedor. Posteriormente, una mera comunicación informativa de los nuevos acreedores a los directivos de la sociedad sería jurídicamentesuficente.

Estos supuestos permitirían tanto la circulación libre del crédito entre adfines, como el tráfico y la libre negociación financiera de los chirographos en los mercados secundarios de crédito, o de deuda corporativa. Los chirographos funcionarían como bonos ${ }^{147}$, a interés fijo o variable y constituirían títulos valores y activos financieros garantizados y transmisibles del crédito ${ }^{148}$. Su carácter de título literal probatorio, firmado y reconocido por la propia mano del deudor (socio, o manceps en nombre de la corporación), e inscrito en los nomina arcaira, es prueba y caución ${ }^{149}$ que asegura al tenedor - acreedor el ejercicio de una acción judicial efectiva (actio ex stipulatu) para hacer efectivo su crédito (sed domestica cautione et chirographo obligaret se ad praestandum ei qui capere non potest ${ }^{150}$ ). En último término, la inscripción de las sucesivas adquisiciones del crédito, fruto de las negociaciones de los títulos de deuda, se haría en los tabulae o nomina arcaira por la sociedad corporativa, para el control de los nuevos acreedores, pero, ya, con simples efectos probatorios. En este sentido, Gayo sostiene que "recte dicemus arcaria nomina nullam facere obligationem, sed obligationem factae testimonium praebere ${ }^{151}$.

$\underline{\text { Títulos valores transnacionales de deuda corporativa privada de las sociedades de }}$ publicanos en los mercados financieros: syngrapha

De la misma forma, el adfin, ciudadano romano, y la corporación deudora podían constituir un préstamo mediante un contrato verbal y escriturarlo literalmente en una syngrapha. Si el adfin acreedor no era ciudadano

\footnotetext{
${ }^{147}$ Burdick W.L., cit. p.437.

${ }^{148}$ D. 31.88.8. Scaevola. LibroIIIResponsorum: "Civibus meis dolego chirographum Gaii Seii":postea codicillisvetuita Seio exigi etabherede petit, utexalterius debitoris debito, quem codicillisnominavit, eandem summam reipublicae daret. Quaesitumest, si posterior idoneus non esset, an integram quantitatem heredes praestare debeant. Respondi heredes rei publicae adversus eum dumtaxat debitorem, qui novissimus codicillis, ut proponitur, designatus est, actionem praestare debere.

${ }^{149}$ Suet. Caes. 17."( ... Vetius etiam chirographum eius Catiliniae datum pollicebatur". Suet. Calig. 12:" . .. ) deque eare et iure iurandoetchirographocavit". Suet.Domit. 1:"Clodium Pollionempraetorem virum in quemestpoema Neronis quodinscribitur Luscio, chirographum eius conversasse et nonnunquam protulisse noctem sibi pollicentis". Aulo Gelio, Not Att. 14, 2,7.

${ }^{150}$ D. 49.14.3, Call. Libro Tertio de Iure Fisci. D. 20.1.26. Mod. Libro IVResponsorum: Pater Seio emancipato filio facile persuasit, ut, quia mutuam quantitatem acciperet a Septicio creditore, chirographum perscriberet sua manu filius eius, quodipse impeditus esset scribere, sub commemoratione domus ad filium pertinentis pignori dandae: quaerebatur, an Seius inter cetera bona etiam hanc domum iure optimo possidere possit, cum patris se hereditate abstinuerit, nec metuiri ex hoc solo, quod mandante patre manu sua perscripsit instrumentum chirographi, cum neque consensum suum accomodaverat patri aut signo suo aut alia scriptura. Modestinus respondit: cum sua manu pignori domum suam futuram seius scripserat, consensum ei obligationi dedisse manifestum est. Gayo Inst. 3.131 y 134.

${ }^{151}$ Gayo Inst. 3.131.
} 
romano, el préstamo se podía redactar directamente en la syngrapha, incluso, sin seguir los moldes jurídicos de la stipulatio romana. En ambos casos, la syngrapha se configuraría como un título valor, o bono garantizado de

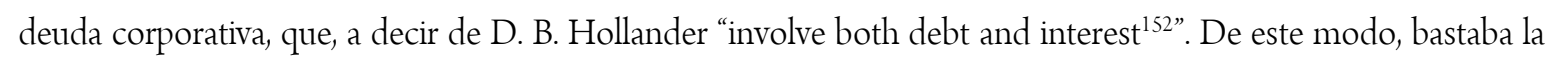
simple transmisión o endoso de la posesión del título valor para que se transmitiese el crédito y su tipo de interés en favor del nuevo tenedor. Cicerón reporta, sin ambages, que la syngrapha es un activo financiero negociable y transmisible, que puede ser utilizada para el cobro de dinero en efectivo, o como letra de cambio, para su descuento bancario, e incluso como un cheque de crédito al portador ${ }^{153}$. Este título valor o bono de deuda

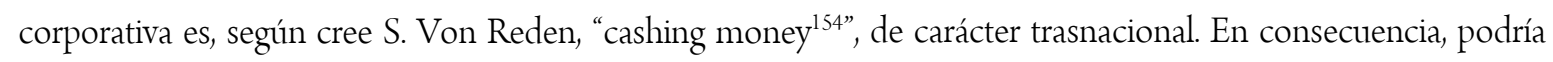
circular libremente por los mercados financieros de Roma y de las provincias ${ }^{155}$. Incluso, sin necesidad del recurso a una stipulatio novatoria. En este sentido, Cicerón reporta en epistularum ad familiares (7.17):

"Tamquam enim syngrapham ad imperatorem, non epistulam attulisses, sic pecunia ablata domum redire properabas, nec tibi in mentem veniebat eos ipsos, qui cum syngraphis venissent Alexandream, nummum adhuc nullum auferre potuisse".

La syngrapha, a diferencia de la chirographa (firmada por el deudor, con carácter probatorio), era rubricada por el acreedor y el deudor ${ }^{156}$. Este activo financiero fue constitutivo de una obligación literal de crédito, es decir, surgía del mismo titulo valor. Y, además, hacía nacer directamente una acción de crédito en favor del tenedor (ex syngrapha agere ${ }^{157}$ ). De este modo, la syngrapha fue un bono o activo financiero de deuda corporativa que posibilitó la expansión de las corporaciones sociales de publicanos por las ciudades y municipios del orbe romano, ya que el endoso y la transmisión de este título valor literal (bills of exchange) permitió la circulación de los flujos de capitales a nivel trasnacional. En este sentido, Cicerón situó en la misma línea de contenidos de su edicto provincial (dictado como procónsul, para Cilicia (53 a. dC. aprox.), los préstamos con interés, las syngraphas y todo lo referente a los publicanos:

“( ... quod duobus generis edicendum putavi. Quorum unum est provinciale in quo est de rationibus civitatum, de aere alieno, de usura, de syngraphis, in eodem omnia de publicanis ${ }^{158}$.

A diferencia del edicto urbano, el edicto provincial regulaba las relaciones comerciales de los nuevos territorios anexionados con Roma. Las syngraphas formaban parte de aquél. Estas últimas permitían la libre circulación trasnacional de capitales y validaban las relaciones y los flujos de crédito entre ciudadanos romanos y hombres de negocios de otras nacionalidades del Imperio. Incluso, fuera de los límites de éste. Así lo cree Gayo:

\footnotetext{
${ }^{152}$ Hollander D., cit. p.46.

${ }^{153}$ Cicerón, Ad Fam. 8.2.2. - 8.4.5. - 8.8.10y ss.

${ }^{154}$ Reden Von S., cit. pp. 111 - 112.

${ }^{155}$ Cicerón, Ad Fam.8.2.2

${ }^{156}$ Pseudo Asconio, Verr.3.36.

${ }^{157}$ Cicerón, Verr.2.4.13.30.

${ }^{158}$ Cicerón, Ad Att.6.1.15.
} 
"Praeterea litterarum obligatio fieri videtur chirographis et syngraphis, id est si quis debere se aut daturum se scribat, ita scilicet si eo nomine stipulatio non fiat. Quod genus obligationis proprium peregrinorum est".

Los créditos de los círculos de adfines constituirían un stock financiero. Este último funcionaría como una especie de paquete de "bonos", o al menos como una especie de cartera de activos financieros. Títulos y obligaciones corporativos garantizados. De renta fija o variable, transmisibles y negociables. Bonos emitidos mediante syngraphas, por los equites, socios publicanos, y sus empresas corporativas (census equestris sociorum publicorum vectigalium ${ }^{159}$ ).

El conjunto de estos activos de los adfines, acreedores de las sociedades de publicanos, constituyó un mercado secundario de deuda corporativa. Este mercado, emergió durante los últimos siglos de la República, y se desarrolló por la intervención financiera de los hombres de negocios, quienes actuaban en órbitas próximas a las corporaciones de publicanos, para satisfacer sus necesidades de capital, y por ende, las del Estado. Así, parece deducirse tanto de los escritos de Cicerón: “omes illius provinciae publicani, agricolae, pecuarii, ceteri negotiatores $(\ldots)^{160 ", ~ c o m o ~ d e ~ S a l u s t i o: ~ " ~}(.$.$) et equites Romanos, milites et negotiatores alios { }^{161 ”}$ y de Paterculus Velleio, en su obra,"La Guerra contra Iugurta ${ }^{162 ": ~ " p e r ~ p u b l i c a n o s ~ a l i o s q u e ~ i n ~ A f r i c a ~ n e g o t i a n t e s ~ c r i m i n a t u s ~ e s t ~ M a r c u s ~}$ Metelli lentitudinem trahentis iam in tertium annum bellum”). Incluso, César, en sus "Comentarios a las Guerras Civiles”, reporta que Pompeyo financió su logística militar y la construcción de buques de guerra con el dinero de las sociedades corporativas de publicanos que operaban en las provincias de Asia, y que se encontraban bajo su mando proconsular: magnam societates earum provinciarum, quas ipse obtinebat, sibi numerae $\operatorname{coegerat~}^{163}$. Además, es presumible, mantener la idea de una continuidad histórica imperial de estos mercados de deuda (a pesar de algunas restricciones de mercado impuestas por Augusto, quien sustituyó, por razones políticas, a las sociedades de publicanos por sus prefectos en algunas provincias imperiales (Judea - Galilea $\left.{ }^{164}\right)$ ).

La syngrapha ofreció grandes ventajas. Esta última es un título valor literal, o bono garantizado, que funciona como una letra de cambio, incluso como un cheque, $y$, además, genera una acción judicial de crédito a favor del último tenedor, o poseedor legítimo. Estas utilidades hicieron de aquélla el activo financiero preferido por los inversores trasnacionales (hombres de negocios de pueblos y naciones del Imperio, sin ciudadanía romana) para colocar sus capitales en el mercado del riesgo de la deuda corporativa, que era emitida por las necesidades financieras de las sociedades de publicanos, "in quo est de rationibus civitatum, de aere alieno, de

\footnotetext{
${ }^{159}$ Marquardt J. K., Historia Equitum Romanorum, LiberIV(1840), p. 20. Tito Livio, Adurbe condita, 43.16.2. Cicerón, Pro Lege Manilia, 2.4

${ }^{160}$ Cicerón, Pro Fontei,cp. 16.

${ }^{161}$ Salustio, Iugurta, 65.

${ }^{162} \mathrm{P}$. Velleius, 2, $11,2$.

${ }^{163}$ C.Julius Caesar, Civ.3.3.

${ }^{164}$ Sanders E.P. “A Verdadeira História de Jesús”, 1993, tercera edición 2004, trad. Teresa Martiho, pp.31.53.
} vol.09, no. 02, Rio de Janeiro, 2016.pp. 1075-1119 1106 
usura, de syngraphis, in eodem omnia de publicanis ${ }^{165 "}$. Mercados de negocios de deuda corporativa, interconectados y dispersos, que se unen a las operaciones industriales de gestión privada de los servicios públicos, que desarrollan las corporaciones de publicanos en todos los territorios delImperio:

"Equitibus Romanis, honestissimis viris, adferuntur ex Asia cotidie litterae, quorum magna res aguntur in vestris vectigalibus exercendis occupatae", (Cicerón, Pro lege Manilia,2.4).

$\underline{\text { Bonos de deuda pública y activos financieros del Estado Romano }}$

En este mercado de deuda corporativa también intervino el Estado Romano. Si creemos a Polibio (6.17) numerosos ciudadanos prometían sus dinero al Estado Romano para la consecución directa por éste, o por las

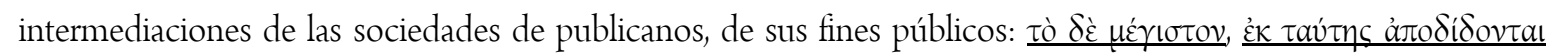

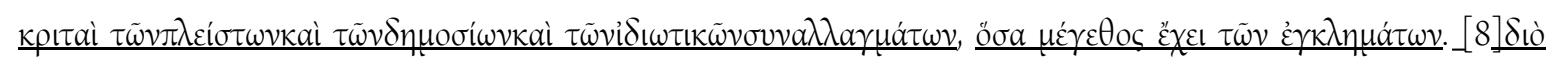

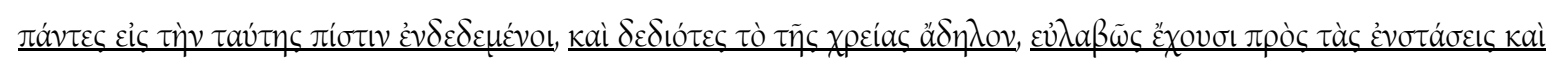

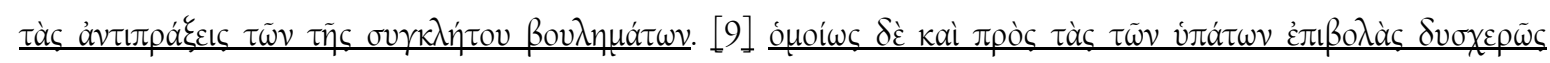

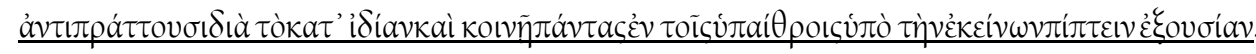

De acuerdo con la información del historiador, los ciudadanos podían participar en la financiación de las competencias públicas del Estado en dos direcciones:

a) Mediante promesas que realizan los ciudadanos, que parecen apuntar a la constitución de préstamos y avales (personales, sponsio, y reales, praedes ${ }^{166}$ ) en favor del Estado (hipótesis que ya fue sostenida por C. Nicolet ${ }^{167}$ ) mediante contratos verbales de sponsio-stipulatio. A tal fin, los ciudadanos se comprometían, en presencia de los magistrados del Estado Romano, a responder con su capital frente al fisco romano.

b) A partir de la información de Polibio, creemos, además, que los magistrados y emperadores formalizaban créditos públicos, mediante contratos verbales que fijaban el capital, el plazo y un tipo de interés a tipo fijo (generalmente elevado) que el Estado se comprometía devolver.

Para garantizar el reconocimiento de la deuda pública, es posible que los magistrados emitieran chirographos de reconocimiento de deuda pública ${ }^{168}$, incluso syngraphas garantizadas ${ }^{169}$ ("letras del Tesoro romano") que circularían, posteriomente, en los mercados finacieros de deuda como bonos y activos financieros de crédito. Bonos que serían negociados por financieros, banqueros y otros hombres del comercio. Actividad que

\footnotetext{
${ }^{165}$ Cicerón, Ad. Att.6,1,15.

${ }^{166}$ Cicerón, Verr.2.1.54.142-55.143.

${ }^{167}$ En este sentido, Nicolet C. "L 'ordre ecuestre à I'époque républicaine (312-43 av.J.C.), I: Définitions juiridiques et structures sociales", París 1966, p. 174.

${ }^{168}$ Cicerón, M. Antonium Oratio Phiilippica, 2.37.96: "Quid ego de commentariis infinitis, quid de innumeranilis chirograhis loquar?”. Cicerón, Philippica 1.7.10. Suet, Caes. 17.Suet.Aug. 87. Suet. Calig. 12. Suet. Dom. 1.

${ }^{169}$ Cicerón, Fam.7.17. Cicerón, AdAtt.5.21.11.Cicerón, Phil.2.37.95. Cicerón, Verr.2.4.13.30. Cicerón, Mur. 17.35. Cicerón, Ami. 26.3.4.
} 
propició su adquisición por los ciudadanos. Este sería una especie de mercado de deuda fiscal que fue generado por las constantes necesidades financieras del Estado romano. Oferta y demanda de créditos públicos para el desarrollo de las competencias del Estado y para dar apoyo a las gestiones de explotación de las sociedades de publicanos. Es evidente que los negocios públicos del Estado repercutín directamente en la vida y en el desarrollo industrial y corporativo de aquéllas. El Estado y las sociedades de publicanos necesitaban captar dinero y recursos constantemente. Es por ello, que la recaudación de impuestos, la explotación de los diferentes sectores demaniales y de los variados servicios fueron yacimientos para la obtención de beneficios públicos (vectigales). Actividades que fueron compartidas por ambos. Roma siempre necesita dinero. Para desarrollar y mantener su nuevo Imperio, las obligaciones financieras y sus cantidades aumentaban desorbitadamente. Tal vez, por ello, y en último término, la mayor corporación de publicanos fue el propio Estado romano.

\section{Mercados de participaciones o cuotas corporativas de renta variable}

La existencia de un mercado de acciones y de participaciones en la Roma republicana ha sido defendido por numerosos autores de la doctrina romanística. Así M. Rostovtzeff sostuvo la existencia en los últimos tiempos republicanos de la Ciudad estado de un comercio de participaciones ${ }^{170}$. En esta dirección se posiciona actualmente R. Zimmermann ${ }^{171}$ quien cree en la emisión y en la circulación de títulos certificados emitidos por las sociedades de publicanos en la Roma republicana. Por su parte, U. Malmendier ${ }^{172}$ reporta, en clara sintonía con el autor anterior, que "we may well call the societas publicanorum the first shareholder company even if the Romans themselves would not have undertaken such categorization ${ }^{173}$ ". Esta autora, sin embargo, tiene dudas sobre la existencia de un mercado de acciones en la Roma antigua: "a stock market there was in ancient Rome may remain in obscurity”. Sobre este punto en particular, M. Rostovzeff no sólo defendió vigorosamente la tesis de la existencia de un mercado de acciones corporativas, si no que, incluso sostuvo que en Roma existió una bolsa de títulos valores que estuvo ubicada en un templo del Foro. En este lugar, los ciudadanos y los hombres de empresa negociaban los precios y las cotizaciones de compra y de venta de las acciones que habían sido emitidas por las grandes corporaciones de publicanos. Esta tesis ha sido recientemente contestada por M.R. Cimma, quien cree que "le partes potevano essere cedute dagli stessi publicani, como è ovvio (Cic. In Vat. 12.29: pro Ro Rab. Post. 2.4) i quali le avessero naturalmente a loro volta ricevute da publicani, ma non che fossero cedute dalla società". Por ello, cuando se habla de cesión, adquisición y venta de partes de una sociedad de publicanos, puede crear equívocos "facendo pensare ad una vera e propia quota in senso moderno dicapitale sociale, quasi una azione

\footnotetext{
${ }^{170}$ RostovzeffM., "TheSocialandEconomic History of The Roman Empire”, (New York, 1957), p.31.

${ }^{171}$ Zimmermann R., cit.p. 468.

${ }^{172}$ Malmendier U.,"Roman Shares", en The Origins of Value: The Financial Innovations That Created Modern Capital Markets,

Oxford University Press (New York, 2005) pp.38.

${ }^{173}$ Malmendier U. cit.p. 40.
} 
liberamente commerciabile ${ }^{174 ”}$. En este sentido, G. Dufour ha realizado un estudio meticuloso de las fuentes literarias, y de las que, según esta autora, no se pueden extraer conclusiones fiables que apoyen aquella hipótesis de la historia económica de Roma: "l'existence de la Borse ou d'un réseau de courtiers n'est donc pas davantage attestée au IIè siècle av.J.-C. qu 'elle ne l' etait au IIIè siècle av.J.-C. ${ }^{175 ”}$.

Con todo, las fuentes literarias se deben conciliar con las fuentes jurídicas para extraer su verdadero valor. Así, desde una óptica jurídica, que es el pilar maestro de nuestro estudio, la sociedad de publicanos fue una corporación privada de responsabilidad limitada, que goza de ropajes de derecho público, autorizados y concedidos por el Estado (perpetuidad, facultades de la personalidad, etc.). Además, este tipo de sociedad capta beneficios públicos en el nombre del Estado o de sus entes territoriales y no negocia con mercancías privadas ni con terceros clientes. Por estas características jurídicas, estas corporaciones son diferentes de las sociedades privadas consensuales voluntarias temporales de responsablidad ilimitada, de compra y venta mercantil, alicuius negotiationis ${ }^{176}$. En este sentido, R. Zimmermann piensa sobre las sociedades de publicanos que "were corporate entities of public law rather than private patnerships ${ }^{177 ”}$. En los últimos siglos de la República sí es seguro que algunas de estas corporaciones de los publicanos adquirieron el permiso jurídico del Estado para actuar como persona jurídica artificial corporativa (habere corpus ad exemplum rei publicae ${ }^{178}$ ). En este sentido W.W. Buckland sostiene que "the position is different in the case of a corporate body ( ... ). In Roman law this group personality could not arise of itself: it was always the creation of th State (...) and when it was once conceived of as fictitious it followed that it must be so created ${ }^{179 ”}$. Este molde jurídico de derecho público personificó a la corporación, la dotó de capacidad jurídica y, por ende, posibilitó la entrada y salida de nuevos socios en el collegii societatis ${ }^{180}$. Al contrario de lo que sucedía en la sociedad consensual sin personalidad jurídica, la renuncia y el ingreso de un socio no conducían a la extinción o la muerte de la sociedad, ni, por ende, de su colegio corporativo. Ambos pervivían, como un ente jurídico personal invisible, al transcurso del tiempo y al cambio de sus miembros ad exemplum rei publicae. Incluso, como sostiene Paulo, la societas publicanorum permanece y sigue operativa aunque se haya ejercitado en vía jurisdiccional una actio prosocio ${ }^{181}$.

Este traje jurídico corporativo se realizó en interés de Estado, pues fue el pilar que propició el desarrollo económico de las sociedades de publicanos de grandes dimensiones (magnam societates earum provinciarum, Caesar, de bell. Civ. 3.3) con volúmenes muy elevados de capital (aguntur certissima populi Romani vectigalia et

\footnotetext{
${ }^{174}$ Cimma Mr. cit. p. 93.

${ }^{175}$ Dufour G., "Societates Publicanorum: Existait-il une Borse ou un Réseau de Courtiers sous la République Romaine?", en R.D.U.S (2011) p. 342 y pp. 343 - 347.

${ }^{176}$ D.17.2.63.8, Ulpianuslibro XXXIadedictum.

${ }^{177}$ Zimmermann R, cit.p. 468.

${ }^{178}$ D.3.4.1.1, Gaiusadedictumprovinciale, libroIII.

${ }^{179}$ Buckland,W.W., "A Text-Book of Roman Law, from Augustus to Justinian”, 1921 (3a ed. revised by Peter Stein) 2007, p. 174.

${ }^{180}$ D.3.4.1.1. Gaiusadedictumprovinciale, libroIII.

${ }^{181}$ D.17.2.65.15. Paul, libri XXXIIadedictum: "etmanentesocietateagiprosocio, velutiquumsocietas vectigalium causacoitaest". _vol.09, nº.02, Rio de Janeiro, 2016.pp. 1075-1119 1109
} 
maxima quibus amissis et pacis ornamenta et subsidia belli requiretis; aguntur bona multorum civium quibus est a vobis et ipsorum causa et rei publicae consulendum, Cicerón, pro lege manilia, 2.6). Estas características y estructuras económicas y financieras permitieron a las grandes sociedades operar en muchos campos de explotación estratégicos del Estado. Sectores que eran generadores de vectigales (impuestos, minas, obras públicas, demanio terrestre y marítimo, logística, ejército, moneda, servicios públicos, importaciones etc.). La estructura corporativa las permitió, además, desarrollar sus actividades en diferentes territorios y provincias de forma trasnacional (equitibus Romanis, honestissimis viris, adferuntur ex Asia cotidie litterae, quorum magnae res aguntur in vestris vectigalibus exercendis occupatae, Cicerón, pro lege manilia, 2.4). Es por ello, que nos encontramos ante un tipo de sociedad que constituyó, durante siglos, uno de los brazos más importantes de la administración financiera romana.

Desde una óptica financiera, las grandes corporaciones trasnacionales de publicanos necesitaron nutrirse constantemente de grandes cantidades de dinero para poder operar. Necesidad también apuntada recientemente por A. Fleckner, quien piensa que "it is again very remarkable the there is hardly any evidence for a societas publicanorum consisting of a larger number of capital providers ${ }^{182}$ ". Esta necesidad generada tanto por el Estado Romano como por las sociedades de publicanos generó mercados de capital. Este se pudo desarrollar posibilitando que terceras personas extrañas a las corporaciones participasen, mediante diferentes cuotas, en la financiación del capital social corporativo.

Por ello, la primera pregunta que nos debemos plantear es si existió en la Roma republicana un título con un valor jurídico equivalente al concepto actual de acción. Como punto de partida, podemos decir, con seguridad, que en la civilización romana sí es seguro que fue acuñado por la jurisprudencia (republicana y clásica) el concepto jurídico de parte o pars societatis. En consecuencia, nos podemos preguntar: ¿Pars societatis es una acción que emite una empresa de publicanos?

Si creemos al jurista clásico Paulo: Soci vectigalium si separatim partes administrent, alter ab altero minus idoneo in se portionem transferri iure desiderat ${ }^{183}$. Según este jurista parte en este supuesto no es una acción. Para Paulo, parte de una sociedad de vectigales es un sector de explotación de una empresa coporativa. Parte de una sociedad industrial de lo público (impuestos, minas, logística militar, etc.) que equivaldría a un sector concreto de explotación, y que puede ser traspasado a terceros mediante precio, con el permiso del magistrado licitador. Incluso, al decir del jurista clásico, podía ser subastada de nuevo y, en consecuencia, adjudicada a un socio más idóneo. De este modo, una sociedad podía adjudicarse varios contratos públicos sectoriales de explotación (veluti

\footnotetext{
${ }^{182}$ Fleckner A., "Corporate Law Lessons from Anciente Rome”, en Harvard Law School Forum on Corporate Governance and FinancialRegulation, June 19(2011),pp. 1-2.

${ }^{183}$ D.39.4.9.4. Paul.libro VSententiarum.
} 
cum societas vectigalium causa coita est propterque varios contractus neutri expediat $\left.{ }^{184}\right)$. Por ejemplo un contrato por cada pozo de un mismo yacimiento minero. La mina es única, pero las partes de explotación (pozos) se dividirían en diferentes subastas y contratos que serían adjudicados por los magistrados licitadores. Así, estas partes podrían ser adquiridas, mediante concesión administrativa, en arrendamiento por la misma sociedad, o por diferentes sociedades de publicanos. Si a juicio del magistrado licitador, el manceps o sus socios no ofrececiesen garantías financieras y fiscales suficientes podrían no ser admitidos a la licitación de una una parte de las licitadas (un pozo, o una salina). Así lo cree Cicerón: "Qui de L. Marcio M. Perpenna censoribus redemerit - socium ne admittito neve partem dato neve redimito ${ }^{185}$. Incluso, de acuerdo con Paulo, una parte (un sector de explotación) también puede ser traspasada por el magistrado a una tercera persona (socio más idóneo). Socio que puede ser un nuevo partícipe de la misma corporación, o bien de otra diferente. En este sentido, J. A. Arias Bonet sostiene que "no hay base para afirmar que la pars se concrete materialmente en algo parecido a un título valor, pero la transmisión bien podía operarse sin necesidad de ello ${ }^{186 "}$.

Desde otra óptica, parte (pars) también es una cuota proporcional que tiene un socio como condueño de la caja social de una corporación de publicanos. Así, tal como nos informa Polibio (6.17), en los últimos siglos republicanos, con el florecer de las corporaciones privadas de rentas públicas, los ciudadanos romanos y también gentes de otras nacionalidades tuvieron la posibilidad de invertir su dinero en sociedades corporativas de negocios públicos. En esta dirección, es sostenible que, ya en los últimos siglos de la República, las sociedades de publicanos dieran lugar al nacimiento de mercados de capitales financieros en los que se ofertaba la posibilidad de adquirir cuotas o participaciones privadas de renta variable. En esta dirección, Tito Livio nos informa de la participación de numerosos socios capitalistas en las corporaciones de publicanos (215 a.C.). Así, a petición del pretor Fulvio, se presentaron a las licitaciones públicas tres sociedades, que estaban compuestas cada una de ellas por 19 socios capitalistas: "Ubi ea dies venit, ad conducendum tres societates aderant hominum undeviginti". Los socios dueños eran partícipes y titulares de cuotas de capital diferentes de numerosas empresas privadas corporativas que gestionaban negocios públicos (no sólo en Roma sino también en Italia y las provincias). Con sus inversiones, los socios entraban a formar parte, como socios dueños, de la empresa de publicanos en proporción a su cuota en el condominio o caja corporativa. La participación representaba un porcentaje proporcional (x\%) respecto al capital social de la corporación (100\%). En este sentido Ciceron pro. Rab. Post. 2.4 sostuvo: Multa gessit, multa contraxit, magnas partis habuit publicorum; credidit populis; in pluribus provincias eius versata res est ( ... ).

\footnotetext{
${ }^{184}$ D.17.2.65.15. Paul, libri XXXII ad edictum: Nonnumquam necessarium est et manente societate agi pro socio, veluti cum societas vectigalium causa coita est propterque varios contractusneutriexpediatrecedere asocietatenecreferturin medium quod ad alterum pervenerit.

${ }^{185}$ Cicerón. In Verr.2.1.55.143.

${ }^{186}$ Arias Bonet J. A. Societas Publicanorum, en AHDE, n. 19, 1948 - 1949, pp. 269. 
Esta noticia, si es considerada de un modo aislado, tal vez, no tendría mucha relevancia. Pero sabemos también por Polibio (6.17) que el Estado Romano y sus entes locales, durante la República, recurrieron a la licitación quinquenal continuada de cientos de concursos públicos para la exacción de distntos impuestos, la explotación de los recursos y la cobertura de sus necesidades públicas ${ }^{187}$. El historiador Polibio se sitúa asi en la misma posición que Tito Livio, y sostiene, además, que en el siglo II a. C. muchos ciudadanos tenían intereses directos tanto en invertir sus capitales para financiar préstamos del Estado (bonos) como para garantizar, mediante avales, las obligaciones fiscales y las cuotas de las sociedades de publicanos. De esta forma, los ciudadanos podían participar en los negocios de las rentas públicas y en la administración financiera de Roma mediante las diferentes concesiones administrativas y arrendamientos periódicos que licitaba el Estado romano ${ }^{188}$. Esta necesidad financiera permanente de la administración romana es precisamente, la creadora del mercado de bonos y de participaciones en torno a las corporaciones de explotación de los negocios e industrias generadores de vectigales.

Los socios privados fundadores de una corporación de rentas públicas y los sucesivos partícipes corrían un riesgo mayor que el de los adfines, pues éstos podían suscribir deuda corporativa y créditos a corto plazo con intereses muy elevados, que eran exigibles e independientes de los resultados, las fluctuaciones, los beneficios y las pérdidas económicas obtenidas por la corporación. Sin embargo, como contraprestación a una mayor asunción de riesgos variables, los socios partícipes suscriptores de cuotas corporativas tenían la posibilidad de obtener beneficios multimillonarios en el reparto de dividendos, es decir, réditos del 100\% al 1000\%. Las participaciones sociales de la caja corporativa cotizaban al alza y a la baja y adquirían diferente valor de mercado. En esta dirección, Cicerón (Vat.12.29) sostenía que las participaciones corporativas cambiaban de precio, es decir, de valor en el mercado: “ ... eripuerisne partis illo tempore carissimas partim a Cesare, partim a publicanis?”. J.A. Arias Bonet cree que las participaciones son transmisibles a terceros. Sin embargo, en relación a este texto de Cicerón, sostiene que "no es incuestionable que se refiera a su valor de venta ${ }^{189 "}$. La palabra carísimas hace alusión directa al valor de cotización de las participaciones en el mercado. En consecuencia, las participaciones del capital social corporativo fluctuaban. Su depreciación y revalorización estaban ligadas directamente a las pérdidas y a los beneficios o réditos empresariales conseguidos en cada ejercicio. Pero también a la abundancia de liquidez, es decir, a la posibilidad de adquisición de capital circulante mediante créditos, o bien mediante la suscripción o adquisición de cuotas sociales, es decir, de participaciones en los mercados de capitalfinanciero.

Además, existieron otros factores, a tener en cuenta, que debieron incidir directamente en la volatilidad o consolidación del precio de las participaciones corporativas. Así, por ejemplo, la fuerza de los socios y sus adfines

\footnotetext{
${ }^{187}$ Ver también, Cimma MR, cit, 39, Milán 1981,pp. 1 - 40.

${ }^{188}$ Polibio, 6.17.3-4.

${ }^{189}$ Arias Bonet J.A., cit. pp. $269-270$.
} 
para ejercer presión política sobre los magistrados y para forzar alianzas de negocios corporativos y empresariales en los sectores de explotación. También, la potencia financiera del crédito de los adfines y la capacidad de solvencia de los socios de la corporación. Parece evidente, además, que el número y la calidad de las adjudicaciones (las ganancias de la reparación de un templo distan de la explotación de un yacimiento aurífero), así como la capacidad de adquisición simultánea de diferentes contratos en la misma o en diferentes explotaciones industriales, la periodicidad de un elevado número de concesiones ad hastam, o, incluso, la potencialidad de la capacidad de adquisición de futuras adjudicaciones (factores puestos de relieve por Tito Livio en su narración de las luchas de las sociedades de publicanos y en la intervención directa del Senado y los Tribunos en las concesiones administrativas del año 184 a. C. ${ }^{190}$ ) fueron otras circunstancias económicas que debieron influir directamente en el precio, en la cotización, y en la compra y venta de las participaciones corporativas. A todo ello, se deben añadir otras causas: los años sucesivos de paz, los periodos prolongados de guerras, así como las amenazas exteriores, tanto terrestres (saqueos, robos etc.) como marítimas (piratas) que sufrió el Estado Romano y sus aliados financieros, es decir, sus sociedades de publicanos. Sin duda, las pestes y las enfermedades, así como otras circunstancias de fuerza mayor debieron originar también situaciones de inestabilidad y volatilidad de las ganancias corporativas. Todas estas situaciones históricas de carácter macroecónomico, debieron influir directamente en las cuentas de resultados de las corporaciones y en las fluctuaciones de sus cuotas corporativas en los mercados de capital financieros. Esto significaba que sobre su valor también podrían influir otras circunstancias que no estaban al alcance del hombre, y otras circunstancias económicas que sí dependían de la voluntad de éste, como la intensidad de la oferta y la demanda de compra y venta de participaciones y de crédito de deuda corporativa en un momento determinado.

Las participaciones son cuotas jurídicas sociales ideales con un valor económico. Tesis que está en plena armonía con el derecho clásico del condominio ${ }^{191}$. Este es conformado por cuotas ideales de los socios que son invertidas en la caja corporativa. Participaciones que, según sostiene C. Salkowski, eran inscritas en los libros de contabilidad de la corporación: "coita igitur vectigalum societate, unicuique certe sociorum et societatis portio, et pars, quam in communem inferre deberet, constitui atque in tabulis societatis prescribi soleat ${ }^{192}$. Estos presupuestos jurídicos posibilitaban que las participaciones fuesen negociadas inter vivos por los comerciantes y grupos de inversores financieros mediante su compra y venta ${ }^{193}$. Incluso fue posible que una cuota social fuese

\footnotetext{
${ }^{190}$ Tito Livio, Aburbecondita, 43.16.2.

${ }^{191}$ Daza Martínez J. y Rodríguez Ennes L., "Instituciones de Derecho Privado Romano", 4a edición, Valencia, 2009, p. 229: "La concreción de la propiedad de cada titular a una parte ideal o cuota de la cosa entera permite a cada condómino la libre disposición de su propia cuota: en las fuentes se alude, en efecto, a la hipoteca (C. 8,20) y usufructo de cuota (D. 7, 6, 5, 2). Y a la legitimación del copropietario en la reivindicatoria de su cuota, si le es conocida la fracción que le corresponde (D. 6, 1, 3,2), o en la forma de vindicatio incertae partis, si seignora (D. 10,3,8,1)".

${ }^{192}$ SalkowskiC., Quaestiones deIure Societatis, PraecipuePublicanorum(1859)pp.60-61.

${ }^{193}$ Cicerón, Vat.12,29. Cicerón, Pro Rab. Post.2, 4.
} 
subdivdida en múltiples subcuotas de participaciones ideales ${ }^{194}$. Hipótesis jurídica que parece encontrar acomodo en Pseudo Asconio, ad Cic. H.l (p. 197 Or):

"Socium ne admittito. Qui tradere aedem debebat. Neve partem dato. Aliud enim socius, aliud participes, qui certam habet partem, non divise agit, ut socius".

Y, ciertamente, también en Valerio Máximo, Factorum et Dictorum Memorabilium 6.9.7:

"Atque ut nobilitati, beneficio paenitentiae se ipsam admonitae respicere, altiora modo suo sperare ausos subtexamus, T. Aufidius, cum Asiatici publici exiguam admodum particulam habuisset, postea totam Asiam proconsulari imperio obtinuit".

Los grupos financieros, compradores de estas subcuotas ideales que han sido fraccionadas de una misma cuota o participación corporativa, serían partícipes ideales de la cuota de un socio corporativo. Es por ello que las participaciones de los socios y las fracciones ideales de los partícipes fuesen objeto de otros negocios inter vivos, como su donación. Incluso, es evidente la posibilidad de que pudiesen ser utilizadas como objeto de garantía de créditos y préstamos (prenda) por sus tenedores. Del mismo modo, las cuotas y sus participaciones se podrín transmitir mortis causa. La corporación societaria, con molde de persona jurídica, podría cumplir así los fines de utilidad pública, colectivos e intemporales, del Estado, y tendría la posibilidad de multiplicar y captar recursos financieros de forma estable y permanente en los mercados de capital. Y, tal vez, estas fueron las principales causas por las que el Estado romano concedió privilegios de derecho público a estas sociedades, pues éstas no se disolvían ni por la transmisión inter vivos de sus participaciones sociales y subcuotas fraccionadas ideales corporativas, ni por la muerte de sus socios.

Ciertamente, si esto no hubiese sido así, tal vez, no habría sido rentable para las grandes sociedades de rentas públicas iniciar, o, al menos, explotar algunos de los negocios ofertados por el Estado. En numerosas ocasiones son necesarias para la viabilidad de aquéllas tanto grandes inversiones de capital como el disfrute de largos plazos de tiempo. Ambos son los pilares necesarios para la explotación en cadena de sectores industriales específicos y estratégicos (por ejemplo, los yacimientos mineros). Las transmisiones inter vivos y mortis causa de las cuotas garantizaban, además, la estabilidad ecónomica intemporal corporativa. Y, por ende, ésta permitía a los compradores y a los herederos, o a los beneficiarios legatarios, no sólo la adquisición de una cuota, que se podía transmitir a las sucesivas generaciones de una misma familia, sino también su adquisición y permanencia estable como socios en la corporación. Así lo cree Pomponio, quien en sus comentarios al Libro XII ad Sabinum sostiene sobre la transmisión mortis causa de las participaciones corporativas que:

"Adeo morte socii solvitur societas, ut nec ab initio pacisci possimus, ut heres etiam succedat societati. Haec ita in privatis societatibus ait: in societate vectigalium nihilo minus manet societas et post mortem alicuius, sed ita demum, si pars defuncti ad personam heredis eius adscripta sit, ut heredi quoque conferri oporteat: quod ipsum ex causa aestimandum est.

\footnotetext{
${ }^{194}$ Kniep F. "Societas Publicanorum", Jena (1896), p. 236, sostiene la posibilidad de que los terceros adquieran, mediante compra, cuotas de la corporación sin convertirse en socios de esta última.
} 
Quid enim, si is mortuus sit, propter cuius operam maxime societas coita sit aut sine quo societas administrari non possit? 195". $^{\text {" }}$

Según el jurista las societates vectigalibus transcienden el tiempo (in societate vectigalium nihilo minus manet societas). El difunto puede transmitir su cuota al heredero y adscribir a éste ultimo, mediante aquélla, como nuevo miembro, a la corporación social (si pars defuncti ad personam heredis eius adscripta sit). Pars defuncti es, sin duda, la cuota proporcional de participación de renta variable que tuvo el difunto en la sociedad recaudadora de rentas públicas (impuestos, obras públicas, minas, salinas, servicios públicos etc.). En esta misma posición se sitúa Ulpiano, quien sostiene que esta característica jurídica es un elemento que diferencia claramentea las corporaciones de rentas públicas de las sociedades consensuales voluntarias:

"In heredem quoque socii pro socio actio competit, quamvis heres socius non sit: licet enim socius non sit, attamen emolumenti successor est. Et circa societates vectigalium ceterorumque idem observamus, ut heres socius non sit nisi fuerit adscitus, verumtamen omne emolumentum societatis ad eum pertineat, simili modo et damnum adgnoscat quod contingit, sive adhuc vivo socio vectigalis sive postea: quod non similiter in voluntaria societate observatur ${ }^{196 "}$.

Estos mimbres jurídicos de las sociedades corporativas se proyectaron al Derecho Intermedio Español con toda su plenitud. Así, Juan De Hevia Bolaños, de acuerdo con la Ley de Partidas V, 10, 1, sostiene que las Compañías pueden hacerse por cierto tiempo o por toda la vida, "y aunque diga que pase a sus herederos, no pasa a ellos, sino es siendo hecha sobre arrendamiento de cosas del Rey, u de algún Concejo de Pueblo ${ }^{197 " . ~ S i ~ s o n ~}$ Compañías Juradas no se extinguen por la muerte de los socios. Las cuotas sociales se podían transmitir inter vivos. Y, además, mortis causa, "no solo a los primeros herederos, sino también a los demas ulteriores al infinito". De este modo, las Compañías que explotan los Arrendamientos Reales son herederas directas de las sociedades corporativas de publicanos romanas.

\title{
SHARES AND CORPORATE FINANCIAL DEBT (CORPORATE BONDS) IN THE CLASSIC ROME
}

\begin{abstract}
Our study directs to be analyzed, from a perspective historical - juridical and economic, to the publicans' companies as juridical creative entities of shares and corporate financial debt in the ClassicRome.
\end{abstract}

Keywords: Shares, Corporate bonds, chirographa, syngrapha, societaspublicanorum.

\footnotetext{
${ }^{195}$ D.17.2.59., Pomp.Libro XIIadSabinum.

${ }^{196}$ D.17.2.63.8, Ulpianuslibro XXXIadedictum.

${ }^{197}$ De Hevia Bolaños, J., Curia Philipica, Vol. II, Madrid, 1797, p.272.
} 


\section{REFERENCIAS BIBLIOGRÁFICAS}

ALBERTARIO, (1913) "Note sulle azioni penali e sulla loro transmissibilità passiva nei limite dell' arrichimento dell' 'erede", en BIDR, 26.

AUBERT J.J. (1994) "Business managers in Ancient Rome: A social and economic study of institores (200 B.C. AD 250. C.)”, Columbia Studies in theclassical tradition, New York, Leiden.

Ibíd.., (2015) “Commerce”, en The Cambridge Companion to Roman Law, New York.

ARANGIO - RUIZ V., (1965, reimpresión 2006) “La Società in Diritto Romano”, Napoli.

ARIAS BONET J.A. (1948 - 1949) “Societas Publicanorum”, en AHDE, n. 19, pp. 218 -303.

BALLESTRI FUMAGALLI, (1987) "L'actio tributoria nel sistema delle opere instituzionali di Gaio, di Giustuiniano e di Teofilo", en "Atti del seminario sulla problematica conttrattuale in diritto romano", Milano, vol. I.

BERETTA, L'annualità delle azioni pretorie nel diritto romano clasico, en RISG 2 (1948) y 3(1949).

BERGER A., (2004), Encyclopedic Dictionary of Roman Law, NewJersey.

BUCKLAND, W.W., "A Text - Book of Roman Law, from Augustus to Justinian”, 1921 (3a ed. revised by Peter Stein) 2007.

BLÁZQUEZ JM. "Las explotaciones mineras y la romanización de Hispania”, en la versión digital del Gabinete de Antigüedades de la Real Academia de la Historia, mantenida por "Antigua: Historia y Arqueología de las civilizaciones".

BURDICKW. L., (2004) “The Principles of Roman Law and their Relation to Modern Law”, New Jersey.

CARCATERRA, (1970), Dolus Bonus, Dolus Malus. Esegesi di D. 4, 3, 1, 2 - 3,Napoli.

CERAMI, P, PETRUCCI, A. (2002), “Lezioni di diritto commerciale romano”, Torino, G. Giappicheli editore

CIMMA M.R., (1981) Ricerche sulle Società di Publicani, Milano, Giuffrè editore.

CHIUSI T., (1993), Contributo allo estudio dell' 'editto de Tributoria actione, Roma.

Ibíd., (2007), “Zum Zusammenspiel von Haftung und organisation im römischen Handellsverkehr”, SZ. 124, 94 ff.

DE HEVIA BOLAÑOS, J. (1797) Curia Philipica, Vol. II, Madrid.

DI PORTO, A. (1985), "Impresa collettiva e schiavo manager in Roma Antica”, Milano, Giuffre 'editore. 
Ibíd. (1997) "Il Diritto commerciale romano. Una zona d'ombra nella storiagrafia romanistica e nelle riflessioni storico - comparative dei commercialisti", en Nozione formazione e interpretazione del diritto, dall' età romana alle esperienze moderne, ricerche dedicate al professor Filipo Gallo, vol. 3, Napoli, JoveneEditori.

DUFOUR G. (2011) “Societates Publicanorum: Existait-il une Borse ou un Réseau de Courtiers sous la République Romaine?”, en R.D.U.S.

FASCIONE L., (2006), Storia del diritto privato romano, G. Giappichelli Editore, Torino.

FERNÁNDEZ DE BUJÁN A., (2013), “Derecho Privado Romano”, Iustel, Madrid. (2011), "Derecho Privado Romano", cuarta edición, Madrid, Iustel. (2012), "Derecho Público Romano", Civitas Pamplona.

FLECKNER A., (2011) “Corporate Law Lessons from Anciente Rome”, en Harvard Law School Forum on Corporate Governance and Financial Regulation, June 19.

FUENTESECA M., (1997) El delito civil en Roma y en el derecho español, Valencia, 1997

GARCÍA CAMIÑAS J., (1994), "La problemática del dolo en el Derecho Romano Clásico", en Homenaje a Jose Luis Murga Gener, Madrid.

GARCÍA GARRIDO M.J., (2000), “Diccionario de jurisprudencia romana”, Madrid.

GOTTOFREDI,J., (1733), “Opera iuridica minora”, West-Frisiae.

GUARINO A. (1989) "Profilo del diritto romano", 7a edizione, Jovene editore, Napoli

HOLLANDER D. (2002), "Money in the Late Republic", New York.

HUNTER W. A., (1920). A systematic and historical exposition of roman law, Edimburgo

IMPALLOMENI, (1955), "L'editto degli edili curuli", Padua.

ISIDORO, Etymologiae.

KASER/KNÜTEL, (2008), "Römisches Privatrecht", 19 ed., München \& 49 Rn. 15

KNIEP F., (1896), “Societas Publicanorum”, Jena.

MALMENDIER U., (2005) “Roman Shares”, en The Origins of Value: The Financial Innovations That Created Modern Capital Markets, Oxford University Press New York.

MICELI M., (2001), "Sulla strutura formulare delle actiones adiecticiae qualitatis", Giappichelli editore, Torino.

NICOLET C. (1966) “L'ordre ecuestre à l'époque républicaine (312-43 av.J.C.)", I: Définitions juiridiques et structures sociales", París.

MITTEIS H. (1908) “Romiches Privatrecht”, Leipzig. 
REDEN VON S. (2010) "Money in classical Antiquity”, Cambridge.

RODRÍGUEZ ENNES L., DAZA MARTÍNEZ J., (2009), Instituciones de Derecho privado Romano, Valencia, Tirant lo Blanch.

SALKOWSKI C., (1859) Quaestiones de Iure Societatis, Praecipue Publicanorum.

SANTERO J.M, (1986) "Aspectos de la política julio-claudia en materia asociativa”, en Estudios sobre la Tabula Siarensis, Sevilla.

ROSTOVZEFF M., (1957) “The Social and Economic History of The Roman Empire”, New York.

SANDERS E.P. (1993) “A Verdadeira História de Jesús”, tercera edición 2004, trad. TeresaMartiho.

SCHILLER A. (1929), "Trade Secret and the Roman Law: Actio Servi Corrupti", Columbia Law Rewiew, pp. 837-845.

SCOTT A.M., (2001), The Civil Law, vols. 1 -2, NewJersey.

SERRAO F. (2002), "Impresa e Responsabilità a Roma nell' età Commerciale”. Pisa, PaciniEditore.

Ibíd. (2000), "Impresa, mercato, diritto, en Seminarios Complutenses de Derecho Romano", vol. XII, Madrid, edición Ursicino Álvárez Suárez, Universidad Complutense deMadrid.

SUÁREZ, G. (2001), “Dirección y administración de empresas en Roma”, Ourense: Servicio de Publicaciones de la Universidad de Vigo.

Ibíd. (2002), "Dirección y administración de empresas II: Actividad aseguradora mutua de empresas terrestres y marítimas”, Ourense, Servicio de Publicaciones de la Universidad deVigo.

Ibíd. (2006), "Management, corrupción de directivos y robótica en las empresas del imperio romano", Ourense, Servicio de publicaciones de la Universidad de Vigo.

Ibíd. (2010), "El peculio como ente jurídico autónomo y matriz de la merx peculiaris" en Revista de Estudios Históricos Jurídicos, n. 32, pp. 119 - 125, editorial de la Universidad Católica deValparaíso.

Ibíd. (2010), "Efectos jurídicos de la comunicación empresa - cliente en el Derecho Romano clásico", en Revista Jurídica online de la Facultad de Jurisprudencia y Ciencias Sociales y Políticas de la Universidad Católica de Santiago de Guayaquil, n. 28, pp. 415 - 427.

Ibíd. (2010), "Efectos jurídicos de la comunicación empresa - cliente en el Derecho romano clásico", en Revista Investigación: Cultura, Ciencia y Tecnología, vol. 4, n. 2 (2010), Ed. Eneas, Novacaixagalicia, Consello Social Universidade de Vigo, ISSN 1889 - 4399, pp. 30 - 36.

Ibíd. (2014) “Derecho de Empresas en la Roma Clásica”, Tirant Lo Blanch, Valencia.

Ibíd. (2014) “Derecho de Empresas en la Roma Clásica”, Dykinson, Madrid. 
SOLAZZI S. (1934) "Per il XIV centenario della codificacione giustinianea” en StudiPavia.

TRISCIUOGLIO A., (2013) “Societas publicanorum e aspetti della responsabità esterna” en Diritto @ Storia, n 11.

VALIÑO, E. (1967), “La Actio Tributoria”, en SDHI, vol. 33, p. 103ss.

VINNII A., (1676), Iurisconsulti Clarissimi, in quatuor Libros Institutionum Imperialium Commentarius Academicus et Forensis, Norimbergae.

VOLTERRA, E., (1986), “Instituciones de Derecho Privado Romano”, Madrid, editorial Civitas.

WATSON ALAN, “Trade Secrets and Roman Law: The Myth Exploded”, en Digital Commons”@ Georgia Law (1996), pp. 19 - 29:http://digitalcommons.law.uga.edu/fac_artchop/476

WILLIAM DUFF, P. (1938) “Personality in Roman Private Law”, Cambridge.

ZIMMERMANN R. (1996) “The Law of Obligations: Roman Foundation of the Civilian Traditon”, New York.

ZWALVE WILLEM, (2002), Callistus 'case. Some legal aspects of roman business activities, L. de Blois \& J. Rich (eds.), The Transformation of Economic Life under the Roman Empire. Proceedings of the second workshop of the international network Impact of Empire (Roman Empire, c. 200 B.C. - A.D. 476), Nottingham, July 4 - 7, 2001 (J.C. Gieben, Amsterdam 2002), pp. 116 - 127.

Este trabajo ha sido realizado en el marco del proyecto DER2013-47662-C2.R financiado por el MINECO (Gobierno de España) yCEDER

Trabalhoenviadoem22 deabrilde 2016.

Aceitoem 22 deabrilde 2016. 